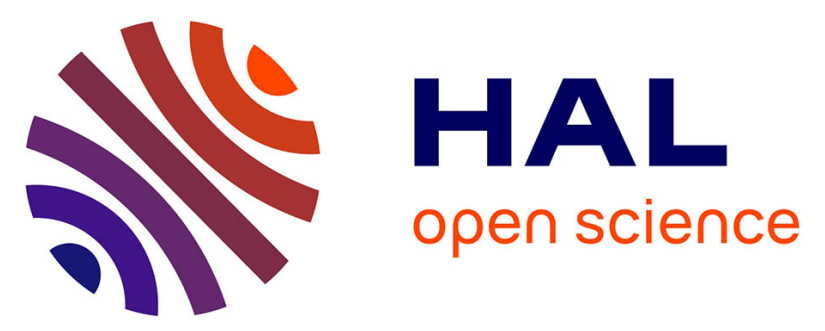

\title{
Subcellular architecture and metabolic connection in the planktonic photosymbiosis between Collodaria (radiolarians) and their microalgae
}

Johan Decelle, Giulia Veronesi, Lekieffre Charlotte, Benoit Gallet, Fabien Chevalier, Hryhoriy Stryhanyuk, Sophie Marro, Stéphane Ravanel, Rémi Tucoulou, Schieber Nicole, et al.

\section{To cite this version:}

Johan Decelle, Giulia Veronesi, Lekieffre Charlotte, Benoit Gallet, Fabien Chevalier, et al.. Subcellular architecture and metabolic connection in the planktonic photosymbiosis between Collodaria (radiolarians) and their microalgae. Environmental Microbiology, 2021, 23 (11), pp.6569-6586. 10.1111/14622920.15766 . hal-03373848

\section{HAL Id: hal-03373848 \\ https://hal.science/hal-03373848}

Submitted on 15 Oct 2021

HAL is a multi-disciplinary open access archive for the deposit and dissemination of scientific research documents, whether they are published or not. The documents may come from teaching and research institutions in France or abroad, or from public or private research centers.
L'archive ouverte pluridisciplinaire $\mathbf{H A L}$, est destinée au dépôt et à la diffusion de documents scientifiques de niveau recherche, publiés ou non, émanant des établissements d'enseignement et de recherche français ou étrangers, des laboratoires publics ou privés. 


\section{Subcellular architecture and metabolic connection in the planktonic photosymbiosis between Collodaria (radiolarians) and their microalgae}

\author{
Johan Decelle $\mathbb{B D}^{1,2^{\star}}$ Giulia Veronesi $\mathbb{D}^{3}, \mathbf{3 , 4 , 5 , 6}$ \\ Charlotte LeKieffre (iD, ${ }^{1}$ Benoit Gallet (1), ${ }^{7}$ \\ Fabien Chevalier, ${ }^{1}$ Hryhoriy Stryhanyuk (D), ${ }^{2}$ \\ Sophie Marro, ${ }^{8}$ Stéphane Ravanel $\mathbb{1}^{1},{ }^{1}$ Rémi Tucoulou, ${ }^{6}$ \\ Nicole Schieber, ${ }^{9}$ Giovanni Finazzi ${ }^{1},{ }^{1}$ \\ Yannick Schwab ${ }^{9}$ and Niculina Musat (1) 2 \\ ${ }^{1}$ Univ. Grenoble Alpes, CNRS, CEA, INRAe, IRIG-LPCV, \\ Grenoble, France. \\ ${ }^{2}$ Department of Isotope Biogeochemistry, Helmholtz \\ Centre for Environmental Research - UFZ, Leipzig, \\ Germany. \\ ${ }^{3}$ CNRS, Laboratoire de Chimie et Biologie des Métaux \\ (LCBM), UMR 5249 CNRS-CEA-UGA, F-38054, \\ Grenoble, France. \\ ${ }^{4}$ CEA, LCBM, F-38054, Grenoble, France. \\ ${ }^{5}$ Université Grenoble Alpes, LCBM, F-38054, Grenoble, \\ France. \\ ${ }^{6}$ ESRF, The European Synchrotron, 71, Avenue des \\ Martyrs, 38043, Grenoble, France. \\ ${ }^{7}$ Institut de Biologie Structurale (IBS), University \\ Grenoble Alpes, CEA, CNRS, 38044, Grenoble, France. \\ ${ }^{8}$ Sorbonne Universités, UPMC Université Paris \\ 06, CNRS, Laboratoire d'Océanographie de Villefranche \\ (LOV), UMR 7093, Observatoire Océanologique, 06230, \\ Villefranche-sur-Mer, France. \\ ${ }^{9}$ Cell Biology and Biophysics Unit, European Molecular \\ Biology Laboratory (EMBL), 69117, Heidelberg, \\ Germany.
}

\section{Summary}

Photosymbiosis is widespread and ecologically important in the oceanic plankton but remains poorly studied. Here, we used multimodal subcellular imaging to investigate the photosymbiosis between colonial Collodaria and their microalga dinoflagellate (Brandtodinium). We showed that this symbiosis is very dynamic whereby symbionts interact with

Received 13 May, 2021; revised 27 August, 2021; accepted 5 September, 2021. *For correspondence. Tel. 00334387825 09. E-mail johan.decelle@univ-grenoble-alpes.fr. different host cells via extracellular vesicles within the colony. 3D electron microscopy revealed that the photosynthetic apparatus of the microalgae was more voluminous in symbiosis compared to freeliving while the mitochondria volume was similar. Stable isotope probing coupled with NanoSIMS showed that carbon and nitrogen were stored in the symbiotic microalga in starch granules and purine crystals respectively. Nitrogen was also allocated to the algal nucleolus. In the host, low ${ }^{13} \mathrm{C}$ transfer was detected in the Golgi. Metal mapping revealed that intracellular iron concentration was similar in freeliving and symbiotic microalgae (c. $40 \mathrm{ppm}$ ) and twofold higher in the host, whereas copper concentration increased in symbionts and was detected in the host cell and extracellular vesicles. Sulfur concentration was around two times higher in symbionts (chromatin and pyrenoid) than their host. This study improves our understanding on the functioning of this oceanic photosymbiosis and paves the way for more studies to further assess its biogeochemical significance.

\section{Introduction}

In the surface layer of oceanic waters, planktonic organisms display a wide range of trophic modes to access energy, such as intimate symbiotic partnerships between taxonomically and physiologically different cells (Decelle et al., 2015). By increasing connectivity and complexity of food webs, planktonic symbioses contribute to carbon and nitrogen fixation, and biogeochemical cycling of different elements (Karl et al., 2012; Thompson et al., 2012; Cabello et al., 2016). The increasing recognition of the ecological role of planktonic symbioses in the global ocean stresses the need to study their physiology and underlying mechanisms that remain largely unexplored. This knowledge gap is because the large majority of planktonic symbioses are not amenable to laboratory culture and their genomes and life cycle are unknown. One of the most prevalent eukaryotic associations in the open ocean is the photosymbiosis between the unicellular 
radiolarian hosts (Rhizaria) and their intracellular symbiotic microalgae (e.g. haptophyte or dinoflagellate) (Decelle et al., 2012; de Vargas et al., 2015; Caron, 2016). Similar to coral reefs, it is a mutualistic symbiosis whereby microalgae provide photosynthetically derived products to the host, which in turn maintains a sheltered and relatively nutrient-rich microhabitat for their microalgae (Matthews et al., 2018). The symbiosis therefore provides a competitive advantage in nutritionally demanding habitats, such as oceanic waters where nutrients (e.g. nitrogen, iron) are extremely limiting. In the context of evolution, we hypothesize that photosymbioses between single-celled hosts and intact microalgae can be a transitional step in eukaryotic plastid acquisition, representing an experimental system to understand how a host cell can control and benefit from the metabolism of a photosynthetic cell.

In the widespread association between the host Acantharia (radiolarians) and the microalga Phaeocystis (haptophyte), the microalga is morphologically transformed into a powerful photosynthetic machinery (e.g. multiplication of voluminous plastids and larger Cfixing pyrenoids), and its nutrient homeostasis is significantly altered (i.e. twofold increase in Fe concentration) (Decelle et al., 2019; Uwizeye et al., 2021b). This partnership can be considered as algal farming where the host has a strong control over the physiology and cell cycle of its microalgae. It is not known whether such morphological and metabolic transformation of algal symbionts is common in other oceanic photosymbioses involving different hosts and microalgal symbionts. Colonial radiolarians (Collodaria) are arguably one of the most abundant photosymbioses in the oceanic plankton (de Vargas et al., 2015; Biard et al., 2016). Collodaria were also among the first observations of symbiotic associations in nature (i.e. T.H. Huxley during the Rattlesnake expedition in 1847). Collodaria, composed of several cells, are known to host thousands of microalgae (the dinoflagellate Brandtodinium nutricula) in their large gelatinous matrix (Anderson, 1976; Probert et al., 2014). Large-scale environmental DNA sequencing projects (e.g. Tara-Oceans) showed that collodarians are widely distributed in the oceans and tend to numerically dominate the plankton community in surface oligotrophic waters (de Vargas et al., 2015; Biard et al., 2017; Faure et al., 2019). In tropical and subtropical waters their total biomass can be as important as the one of the traditional zooplankton, such as copepods (Biard et al., 2016). High densities of colonies (16 000-20000 colonies $\mathrm{m}^{-3}$ ) have been reported in different oceanic regions, with marked seasonal episodes of blooming (Swanberg and Caron, 1991; Dennett et al., 2002). Their significant participation to carbon fixation (through photosynthesis of their algal symbionts) and carbon export to the deep ocean (Caron et al., 1995; Guidi et al., 2016) make them key players in oceanic waters. For instance, primary production of Collodaria can be more than four orders of magnitude greater than that in the same volume of the surrounding seawater (Caron et al., 1995). In addition to energy provided by their symbionts, in situ observations and culture experiments have also described collodarians as active predators feeding on a broad range of prey (e.g. copepods, ciliates, phytoplankton or bacteria) therefore contributing to oceanic food webs (Swanberg and Caron, 1991).

The ecological success of radiolarian photosymbioses in the ocean involving the microalga Brandtodinium must rely on the capacity of the partners to intertwine their metabolism and on the efficiency with which they exchange nutrients, such as carbon and the poorly available macronutrients (e.g. nitrogen) and trace metals (e.g. iron). However, the metabolism and physiology of the microalga Brandtodinium in symbiosis are not known, as well as the underpinning mechanisms of the host to accommodate this microalga. The study of this uncultured cell-to-cell symbiosis, where partners cannot be separated, calls for dedicated subcellular imaging methods that maintain the physical integrity of the hostsymbiont association. Here, using multimodal subcellular imaging ( $3 \mathrm{D}$ electron microscopy and mass spectrometry and X-ray fluorescence imaging), we investigated the cellular architecture and metal homeostasis of the microalga Brandtodinium in free-living and symbiotic stages, as well as the carbon and nitrogen flux and transfer between both partners.

\section{Results and discussion}

Cellular architecture of the microalga Brandtodinium in free-living and symbiotic phases

The metabolism and bioenergetic features of a microalgal cell can be manifested by its cellular architecture organization, such as the arrangement and volume of energyproducing organelles and vacuoles (Uwizeye et al., 2021a). Using $2 \mathrm{D}$ and $3 \mathrm{D}$ electron microscopy [transmission electron microscopy (TEM) and focused ion beam-scanning electron microscopy - FIB-SEM respectively], the cellular organization of the microalga Brandtodinium was investigated in the free-living cells (i.e. maintained in artificial culture medium and isolated from Mediterranean collodarians) and symbiotic stage within the host Collodaria collected in surface waters of the Mediterranean Sea. Compared to free-living, the round-shaped microalgae have lost their thick theca in symbiosis (Fig. 1). Of note, plastids, which were located around the cell periphery, occupied a twofold larger surface area of the cell in symbiosis (mean $\pm \mathrm{SD}=26 \pm 6 \%$ of the cell surface; $n=20$ ) compared to the free-living stage (mean $\pm \mathrm{SD}=12 \pm 2 \% ; n=41$ cells) (Fig. 1G). In order to 

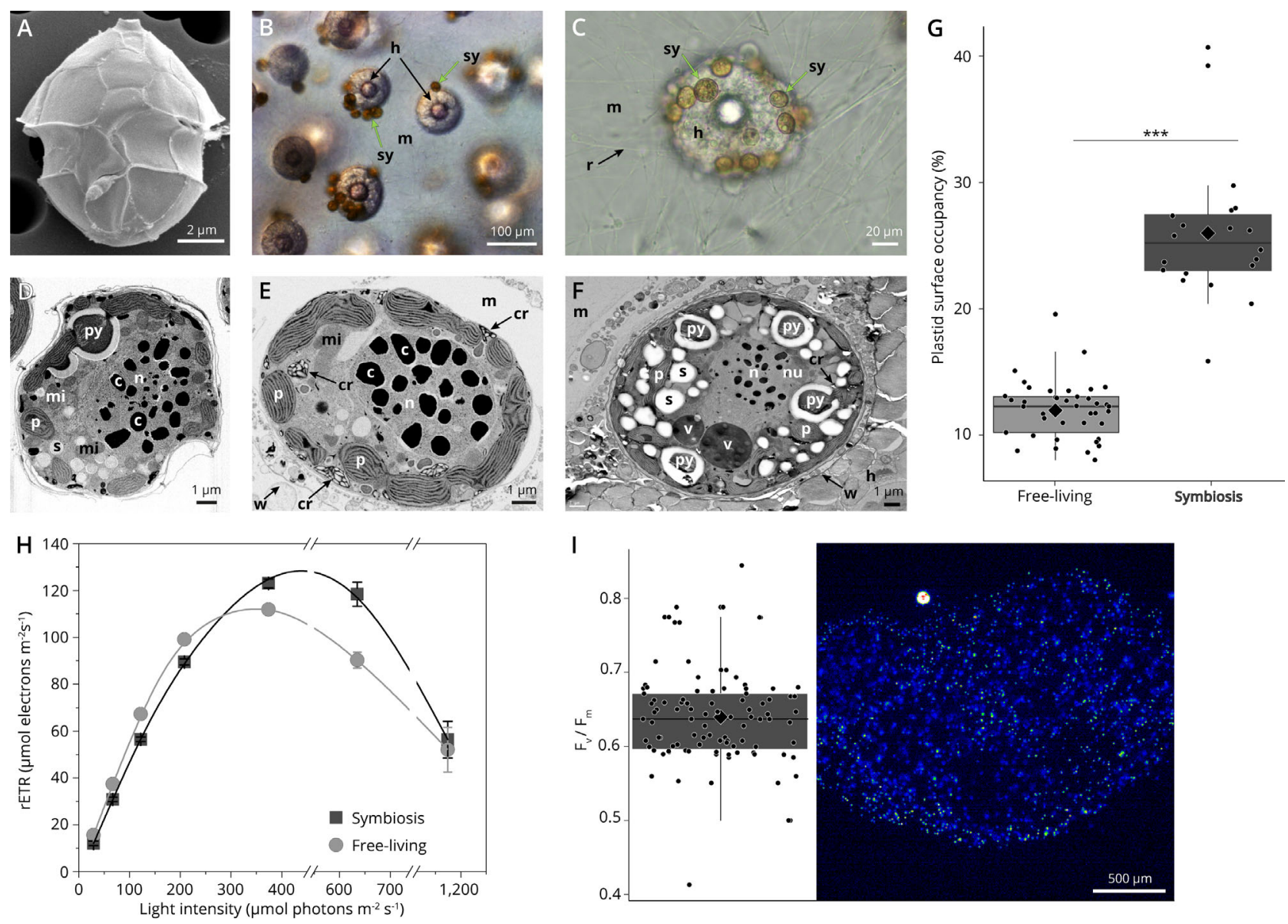

Fig. 1. Ultrastructure and photophysiology of the microalga Brandtodinium in free-living and symbiotic stages within collodarians hosts.

A. External morphology of Brandtodinium with its thecal plates revealed by scanning electron microscopy.

B. Colony of Collodaria observed with light microscopy, composed of several host cells (black arrow, $\mathrm{h}$ ) and multiple symbiotic microalgae (Sy; green arrow) embedded in the gelatinous matrix $(m)$.

C. A zoom-in on a host cell surrounded by symbiotic microalgae and cytoplasmic strands (r; rhizopodia).

D. Ultrastructure of free-living Brandtodinium revealed by transmission electron microscopy (TEM).

$\mathrm{E}$ and $\mathrm{F}$. TEM micrographs showing the ultrastructure of symbiotic Brandtodinium within the Collodaria.

G. Plastid surface area occupancy (\% of the cell surface) in free-living and symbiotic stages of Brandtodinium calculated from TEM micrographs. Plastid surface area is statistically higher in symbiosis $(t=14.67, d f=24.75, p<0.0001 ; N=59$; based on Cook's distances and high leverage, two outlying data points were excluded from the analysis because of their high influence).

$\mathrm{H}$. Photosynthetic efficiency measured by the relative electron transfer rate (rETR) for free-living (light grey green circles; $n=4)$ and symbiotic (dark grey squares; $n=4$ ) microalgae over a range of light intensities up to $1200 \mu \mathrm{mol}$ photons $\mathrm{m}^{-2} \mathrm{~s}^{-1}$.

I. $F_{\mathrm{v}} / F_{\mathrm{m}}$ values measured by a PAM microscope from each individual symbiotic microalgal cells within a colony. $\mathrm{n}$ : nucleus; c: condensed chromatin (chromosome), py: pyrenoid; p: plastid; s: starch grain; h: Host cell (Collodaria); m: matrix; mi: mitochondria; w: membranous envelope of the host; cr: nitrogen-rich crystals; r: rhizopodia. [Color figure can be viewed at wileyonlinelibrary.com]

confirm and better understand this morphological change of the photosynthetic machinery, we conducted morphometric analyses using 3D electron microscopy (FIB-SEM) on four symbiotic Brandtodinium cells and three free-living cells maintained in culture. 3D reconstructions, which were based on >1000 aligned electron micrographs for each cell, showed that the volume of the microalgal cell was similar in both stages (333 $\pm 82 \mu \mathrm{m}^{3}, n=3$ and $305 \pm 44 \mu \mathrm{m}^{3}, n=4$ in free-living and symbiosis respectively). The plastid is a reticulated and thick network (Fig. 2A and D). Morphometric analyses confirmed that the plastids were more voluminous in symbiosis $\left(81 \mu \mathrm{m}^{3} \pm 12\right)$ compared to free-living cells $\left(55 \mu \mathrm{m}^{3} \pm 10\right)$ and can occupy up to $31 \%$ of the cell volume (16.8 $\pm 1.5 \%$ on average in free-living) (Fig. $2 \mathrm{G}-\mathrm{H}$; Table S1). This expansion of the photosynthetic machinery was also found in the microalga Phaeocystis within acantharian hosts, suggesting that it may be a common morphological trait in planktonic photosymbiosis (Decelle et al., 2019; Uwizeye et al., 2021a). Regarding the carbon fixation capability of Brandtodinium, 3D reconstructions unveiled various numbers of pyrenoids in individual cells (i.e. from one to four) in both life stages but in symbiosis, pyrenoid occupancy in the cell was slightly larger $(2.4 \pm 0.3 \%)$ than in free-living cells $(1.7 \pm 0.2 \%)$ (Fig. $2 \mathrm{C}$ 

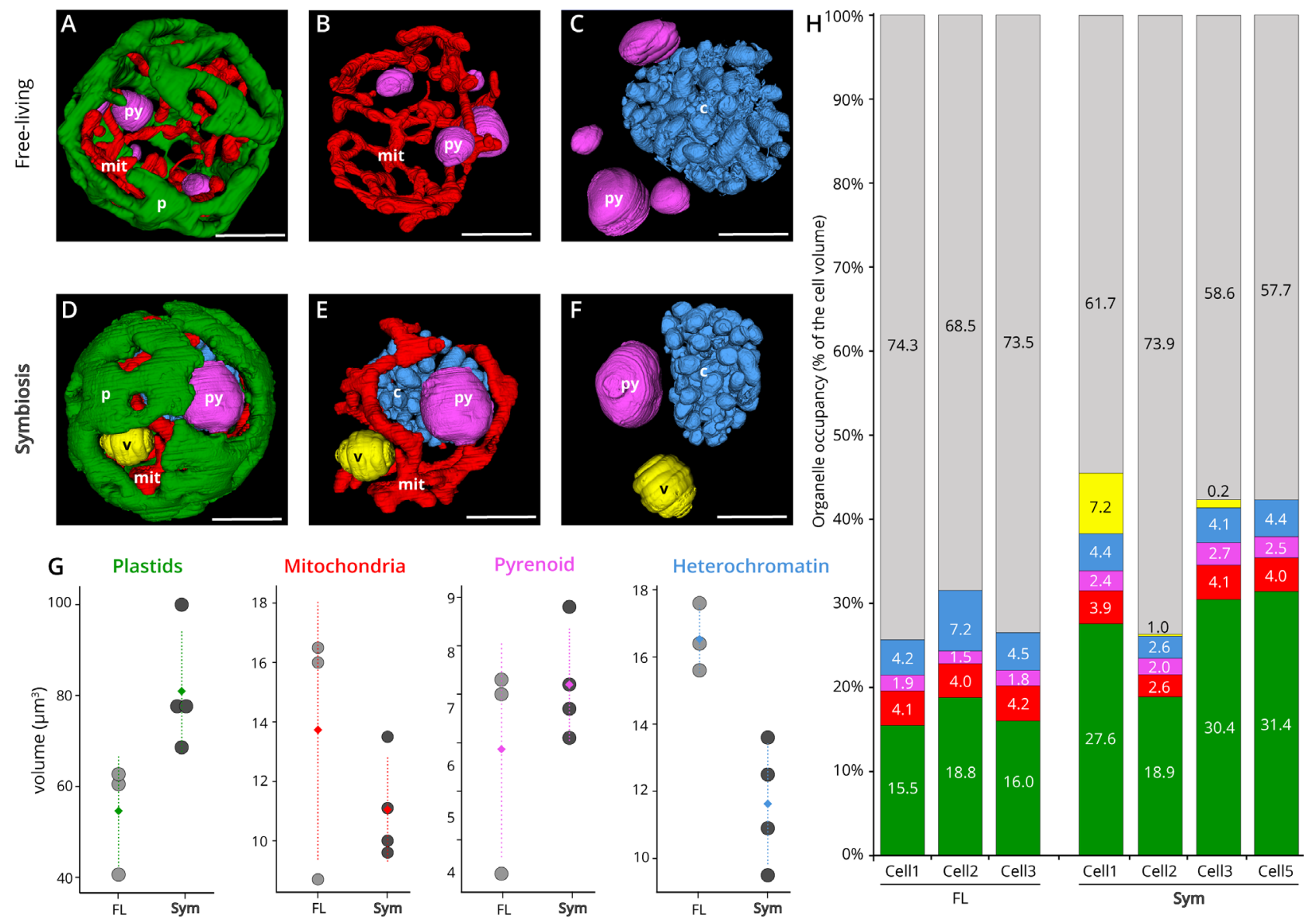

Fig. 2. Cellular architecture in $3 \mathrm{D}$ and morphometrics of the microalga Brandtodinium in free-living and symbiotic stages revealed by FIB-SEM imaging.

A-C. Topology of the plastid (green), mitochondria (red), pyrenoid (purple) and condensed chromatin (chromosomes, light blue) in a free-living microalgal cell. Scale bar: $3 \mu \mathrm{m}$.

D-F. Topology of the plastid (green), mitochondria (red), pyrenoid (purple), vacuole (yellow) and condensed chromatin (chromosomes, light blue), in a symbiotic microalgal cell. Scale bar: $3 \mu \mathrm{m}$.

G. Volume $\left(\mu \mathrm{m}^{3}\right)$ of different organelles of the microalga Brandtodinium in free-living $(n=3)$ and symbiotic $(n=4)$ stages, such as plastids, mitochondria, pyrenoid and heterochromatin (chromosomes), calculated based on 3D reconstructions.

$\mathrm{H}$. Volume occupancy of organelles (\% of the cell volume) in three free-living algal cells and four symbiotic algal cells. [Color figure can be viewed at wileyonlinelibrary.com]

and F). In addition, we observed a correlation between volumes of plastids and pyrenoid ( $R=0.81, p=0.028$; Pearson correlation), suggesting an energetic coupling between the light-dependent and light-independent photosynthetic reactions as found in some microalgae (Uwizeye et al., 2021a) (Fig. S1). In the multiple-stalked pyrenoids, we observed that thylakoid membranes (called tubules) penetrated like fingers the $\mathrm{C}$-fixing organelle, which is covered by a thick starch sheath (Fig. 3A). These tubules are thought to be enriched in carbonic anhydrase in order to ensure high local concentration of $\mathrm{CO}_{2}$ for the Rubisco in the matrix (Engel et al., 2015; Meyer et al., 2017).

To test possible consequences of this plastid expansion on the photophysiology of Brandtodinium, we characterized photosynthetic parameters in vivo, based on chlorophyll fluorescence imaging. We found that the photosynthetic efficiency, measured through the electron transfer rate (ETR) parameter on microalgae and collodarian colonies, which is related to carbon assimilation (Genty et al., 1989), was similar in free-living and symbiotic stages of the microalga in a light range from 20 to $400 \mu \mathrm{mol}$ photons $\mathrm{m}^{-2} \mathrm{~s}^{-1}$, but differed when light was further increased (being 1.3 times higher in symbiosis in the $400-1000 \mu \mathrm{mol}$ photons $\mathrm{m}^{-2} \mathrm{~s}^{-1}$ range) (Fig. $1 \mathrm{H}$ ). In addition, photoprotective responses, evaluated though the non-photochemical quenching parameter (NPQ) of photosystem II was lower in the symbiotic stage from 200 to $1200 \mu \mathrm{mol}$ photons $\mathrm{m}^{-2} \mathrm{~s}^{-1}$ (being three times lower at $400 \mu \mathrm{mol}$ photons $\mathrm{m}^{-2} \mathrm{~s}^{-1}$ ) (Fig. S2). Overall, these data suggest that the photosynthetic capacity is 

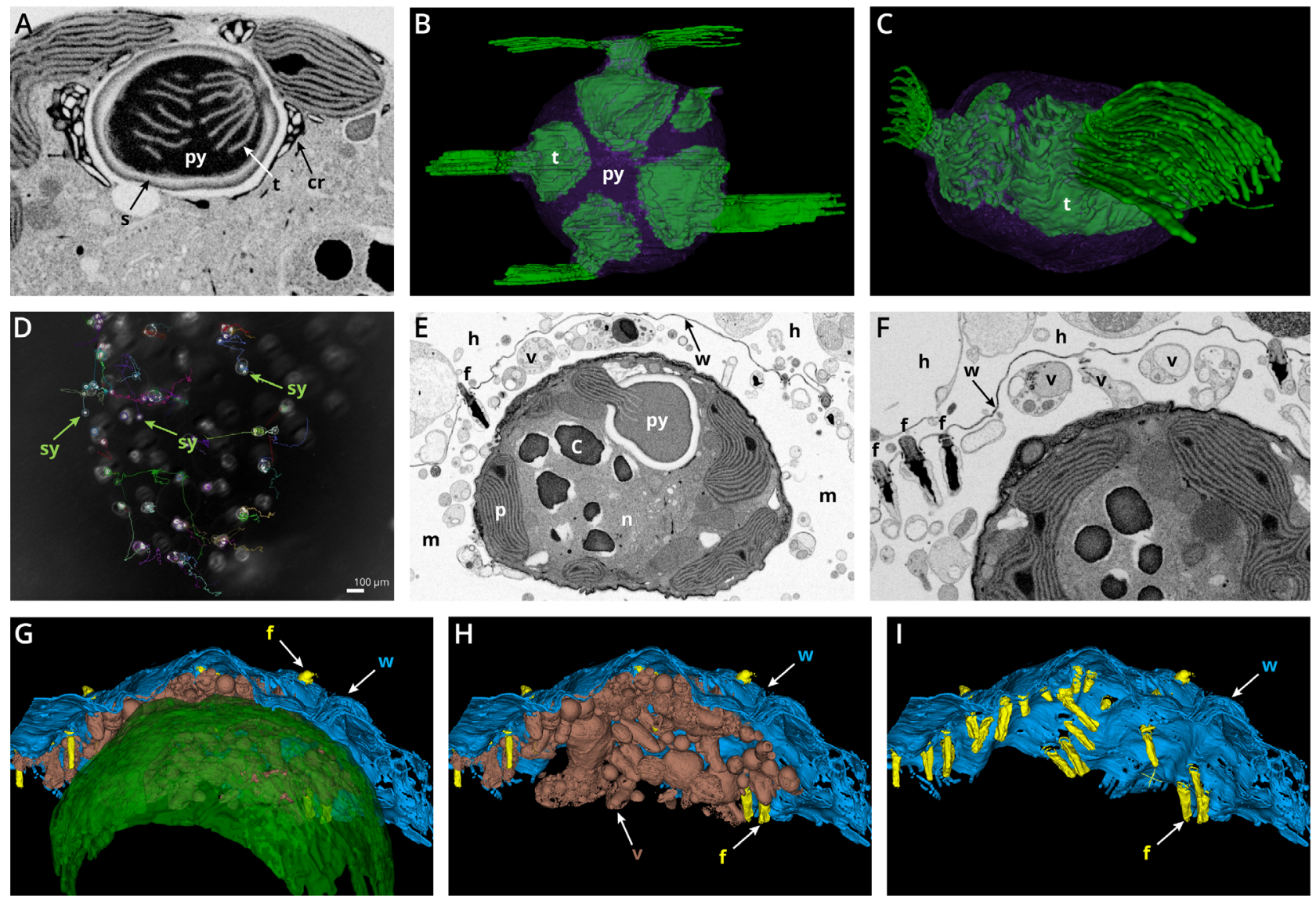

Fig. 3. Pyrenoid architecture and integration of the symbiotic microalga in the host.

A-C. Pyrenoid architecture of the microalga Brandtodinium visualized by TEM (A) and FIB-SEM reconstruction (B and C). Pyrenoid (purple) is surrounded by a starch sheath and penetrated by thylakoid membranes ( $t$, in green) from different stalks.

D. Snapshot image of a particle tracking video conducted on a light microscope (See Video S1) where trajectories of symbiotic microalgae (Sy; indicated by a green arrow) during few hours are visible inside the colony (coloured lines). Symbionts were not associated to a specific host cell but interacted with several host cells.

E-F. EM micrographs showing the physical integration of a symbiotic microalga (Brandtodinium), which was surrounded by numerous vesicles (v) in the ectoplasm (matrix) and in close contact with the symbiont.

G-I. 3D reconstruction after FIB-SEM of the host-symbiont integration with a focus on the numerous vesicles ( $v$, brown structures) between the membranous envelope of the host ( $\mathrm{w}$, blue) and the symbiotic microalga (green). Piston-like structures (called fusules) were also observed at pore sites of the membranous envelope of the host (w). These organelles are known to inject host endoplasm into the matrix (=ectoplasm) as a vacuolated network (Anderson, 1976). [n: nucleus; c: condensed chromatin (chromosome), py: pyrenoid; p: plastid; f: fusules; h: host cell (Collodaria); m: matrix; w: envelope of the host; cr: nitrogen-rich crystals; v: vacuoles in the matrix]. [Color figure can be viewed at wileyonlinelibrary.com]

more efficient in symbiotic algae at high light [i.e. light intensity typically experienced in surface waters (Breitbarth et al., 2008)], i.e. that absorbed photons are better used for photosynthetic electron flow (ETR) and therefore less dissipated as heat. To test if $F_{\mathrm{v}} / F_{\mathrm{m}}$ (maximum quantum efficiency of PSII photochemistry) is homogeneous among the symbiont population, this parameter was measured on individual algal cells within a colony collected in surface waters (Fig. 1I). The average single-cell $F_{\mathrm{v}} / F_{\mathrm{m}}$ value was $0.64 \pm 0.07(n=52$ cells), consistent with earlier findings at the symbiont population level (0.58) (Villar et al., 2018). The low variability observed among the symbiont population of the colony may reflect relatively homogeneous physiological states of symbiotic microalgae in a colony.

As for the respiratory machinery, the mitochondria formed a reticulated network located between the plastids and nucleus, in close proximity with plastids in some cellular regions (Fig. 2B and E). Total volume of mitochondria tended to be not different between free-living $\left(14 \mu \mathrm{m}^{3} \pm 4\right)$ and symbiotic cells $\left(11 \mu \mathrm{m}^{3} \pm 2\right)$, occupying a constant $4 \%$ of the cell volume with similar topology in both stages (Fig. $2 \mathrm{G}$ and $\mathrm{H}$ ). Based on this finding, it is tempting to propose that the respiratory activity of the microalgal cell is not substantially different between freeliving and symbiosis. The nucleus of the microalga (also 
called the dinokaryon) was centrally located and contained typical condensed, rod-shaped chromosomes of different sizes and one or two nucleoli (Gautier et al., 1986) (Fig. 2C and F). The volume occupancy of the nucleolus in the cell was similar in both life stages $(0.26 \pm 0.4 \%$ and $0.30 \pm 0.07 \%$ on average in free-living and symbiosis respectively) (Table S1). But total volume of condensed chromatin tended to be slightly lower in symbiosis ( $12 \mu \mathrm{m}^{3} \pm 2 ; 3.9 \pm 0.7 \%$ of occupancy) compared to that in free-living cells $\left(17 \mu \mathrm{m}^{3} \pm 1 ; 5.3 \pm 1.4 \%\right.$ of occupancy) (Fig. 2G). The number of chromosomes including electron-dense chromatin structures in the nucleoplasm greatly varied from 44 to 88 in symbiotic cells and from 64 to 179 in free-living cells (Fig. S3). This reflects the dynamic level of chromatin compaction, which is known to vary across the life cycle of dinoflagellates (Blank, 1987). For instance, in G1 phase, there are numerous small structures protruding from the chromosomes towards the nucleoplasm (Bhaud et al., 2000), which could correspond to our observations in free-living cells (Fig. 2A). Although this needs to be confirmed with more cells, this observation may indicate that the symbiotic microalga is at a different life phase and may be related to the slower growth of symbiotic Brandtodinium as suggested by transcriptomics in a different host species and known in corals (Davy et al., 2012; Liu et al., 2019). For instance, doubling times of the dinoflagellate Symbiodiniaceae within corals can exceed 10 days and up to 70 days while in culture the doubling times are generally 2-5 days (Davy et al., 2012). Yet, contrary to photosymbiosis in Acantharia (Uwizeye et al., 2021b), symbiotic Brandtodinium cells had the same volume as in free-living and were observed to divide within the host colony (Fig. S4), so there is no complete inhibition of symbiont division.

\section{Structural connectivity between the host and its symbiotic microalgae}

The physical integration of symbiotic microalgae within the host was then investigated at the nanoscale to identify the possible routes of metabolic exchanges between cells. In Collodaria, microalgae were outside the host endoplasm, being embedded in the translucent gelatinous matrix of the colony (i.e. ectoplasm) (Fig. 3). Cytoplasmic strands (called rhizopodia) embraced microalgae and are known to control their distribution in the matrix [Fig. 1 (Anderson, 1976)]. Particle tracking from light microscopy time-lapse showed that microalgae can move in this matrix (up to hundreds of microns $\min ^{-1}$ ) and stop by different host cells for few minutes (Fig. 3D and Video S1). Of note, TEM and FIB-SEM reconstructions revealed a network of numerous vacuoles in the matrix located between the host cell and the symbiotic microalgae, sometimes physically associated to both cells (Fig. 3E-I). In $3 \mathrm{D}$, some of these round-shaped vacuoles were connected to each other and very likely ensure metabolic connection between the host and the microalgae. In addition, piston-like structures (called fusules) visible on the capsule membranous envelope of the host are known to inject host endoplasm into the matrix as a vacuolated network (Anderson, 1976). Overall, Collodaria photosymbiosis is a dynamic system where host cells interact with several microalgae within the 'greenhouse-like' colony through time via vesicles, raising questions about the nutrient flow between cells and more generally the metabolic connection.

\section{Subcellular visualization of the incorporation and allocation of ${ }^{13} \mathrm{C}$ and ${ }^{15} \mathrm{~N}$}

To better understand the metabolic crosstalk between the host and the microalgae and more specifically the exchanges and allocation of carbon and nitrogen, we incubated collodarians in ${ }^{13} \mathrm{C}$-bicarbonate and ${ }^{15} \mathrm{~N}$ ammonium for a 3-h light period in filtered natural seawater, cryo-fixed with high pressure freezing and prepared them for nanoSIMS (Nanoscale Secondary Ion Mass Spectrometry) (see Experimental procedures). Five different microalgae from two distinct collodarian colonies were analysed. NanoSIMS analyses revealed changes in ${ }^{13} \mathrm{C}$ and ${ }^{15} \mathrm{~N}$ fractions (\% of ${ }^{13} \mathrm{C}$ or ${ }^{15} \mathrm{~N}$ out of total $\mathrm{C}$ or $\mathrm{N}$ ) in different organelles. Since changes in ${ }^{13} \mathrm{C}$ and ${ }^{15} \mathrm{~N}$ fractions are not linearly proportional to cellular activity, we also calculated the assimilation activity expressed as the relative assimilation $K_{\mathrm{A}}$ in atom\% (Stryhanyuk et al., 2018). In the symbiotic microalgae, ${ }^{13} \mathrm{C}$ fraction was mainly detected in multiple starch grains distributed in the cytoplasm (mean $\pm \mathrm{SD}=21 \pm 2$ atom $\%, n=38$ ) and in the extra-plastidial starch sheaths surrounding the pyrenoids (mean $\pm \mathrm{SD}=19 \pm 1$ atom $\%, n=12$ ) (Fig. 4; Table S2). The relative carbon assimilation $\mathrm{Ka}$ of $25 \pm 4$ atom\% in starch grains and $23 \pm 2$ atom\% in starch sheaths were calculated [see Experimental procedures for more details and Stryhanyuk et al., 2018]. Lower Ka was revealed from starch of the second collodarian colony (10 \pm 3 atom\% and $9 \pm 2$ atom\% in cytoplasmic grains and sheaths respectively). Starch grains were observed both in free-living and symbiotic stages by TEM observations (Fig. 1) and can represent a volume of $c$. $5 \%$ of the cell as calculated from FIB-SEM reconstructions (Fig. 4, Table S1). They were scattered in the cytoplasm and adjacent to plastids and pyrenoids. ${ }^{13} \mathrm{C}$ labelled starch granules were also observed in another planktonic photosymbiosis in foraminifera involving the dinoflagellate Pelagodinium beii (Lekieffre et al., 2018). The observed assimilation activity pattern in photosymbiosis 

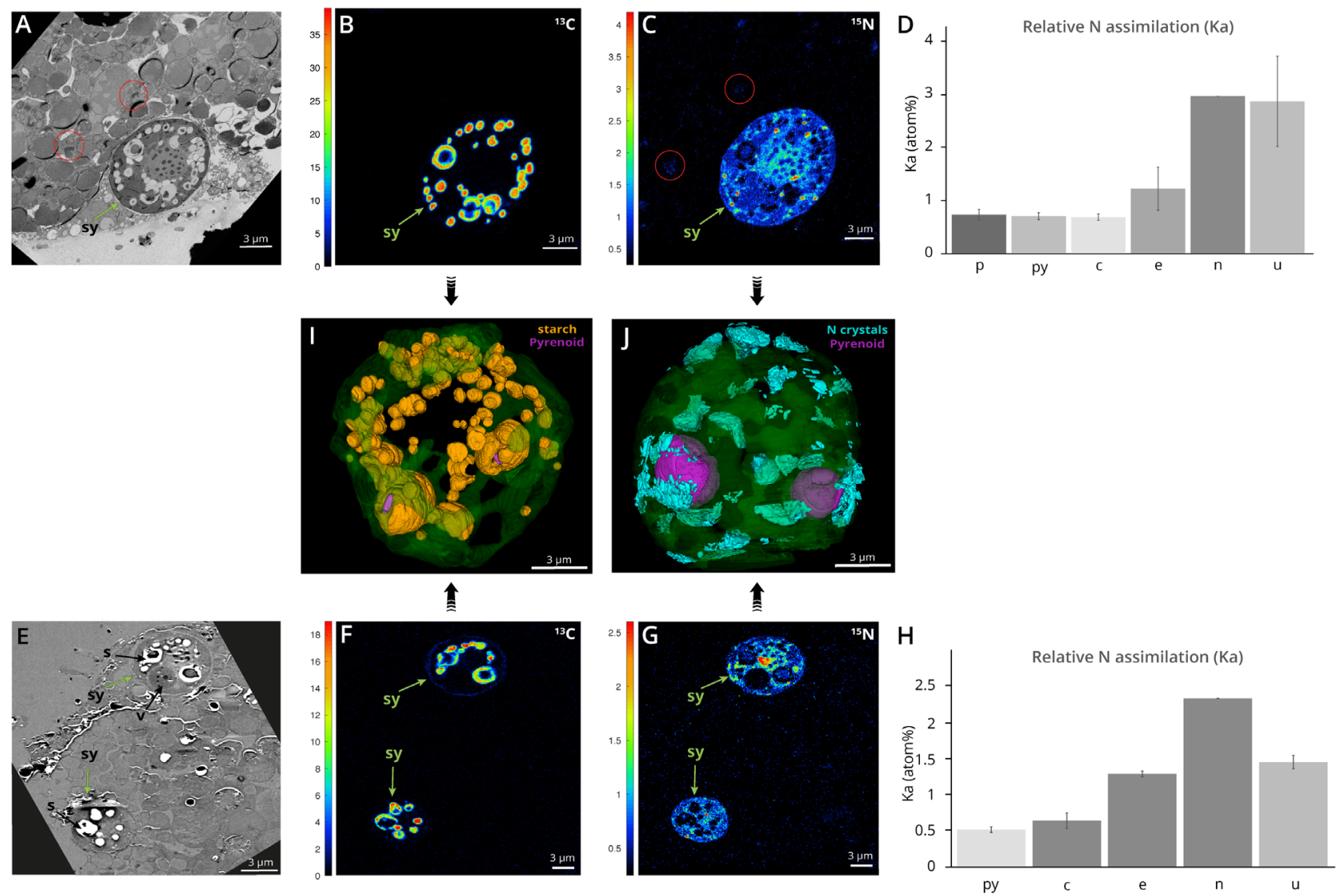

Fig. 4. Carbon and nitrogen flux in the symbiotic cells as revealed by correlated TEM-nanoSIMS and ${ }^{13} \mathrm{C}$-bicarbonate and ${ }^{15} \mathrm{~N}$-ammonium labelling.

A and E. TEM micrographs of the cellular areas analysed by nanoSIMS, showing three symbiotic microalgae (Sy; indicated by a green arrow) and their host cell from two different colonies. Host Golgi are surrounded by a red circle.

$\mathrm{B}$ and F. NanoSIMS mapping showing relative carbon assimilation $(\mathrm{Ka})$ following ${ }^{13} \mathrm{C}$-bicarbonate $3 \mathrm{~h}$-incubation in starch granules and starch surrounding the pyrenoids.

$\mathrm{C}$ and G. NanoSIMS mapping showing the relative nitrogen assimilation (Ka) following ${ }^{15} \mathrm{~N}$-ammonium $3 \mathrm{~h}$-incubation in symbiotic microalgae, more particularly in purine crystals (red hotspots) and in the nucleolus. The latter compartment corresponds to the red hotspot in the middle of the upper cell in panel G. Nitrogen assimilation was also detected in the Golgi apparatus of the host cell, highlighted by the red circles in C (see also Fig. S5).

$\mathrm{D}$ and $\mathrm{H}$. Averaged relative $\mathrm{N}$ assimilation (Ka) measured by nanoSIMS in different organelles of the symbiotic microalgae from two different colonies (A8 and A7) ( $n=3$ cells in D; $n=2$ cells in $\mathrm{H})$.

I. 3D reconstruction after FIB-SEM imaging of the starch (orange) that assimilated carbon. In the algal cytoplasm, starch was contained in grains and also surrounding the pyrenoids (purple) and closely associated to the plastid (green, transparent).

J. 3D reconstruction after FIB-SEM imaging of $\mathrm{N}$-rich purine crystals (light blue) that were localized at the periphery of the cell in close association with the pyrenoids (purple). py: pyrenoid; c: condensed chromatin; e: euchromatin+nucleoplasm; n: nucleolus; u: purine crystals. [Color figure can be viewed at wileyonlinelibrary.com]

confirms that the newly fixed carbon is rapidly stored by the microalgae as glucose polymers.

In the host cell, after $3 \mathrm{~h}$ of incubation, low ${ }^{13} \mathrm{C}$ fraction was detected and only in the secretory vesicles of multiple Golgi apparatus (1.33 \pm 0.05 atom\%, corresponding to a Ka of $1.64 \pm 0.12$ atom\% (Fig. 4, Fig. S5). This organelle is known to serve as a carbohydrate factory to process oligosaccharide side chains on glycoproteins and glycolipids (Mellman and Simons, 1992). Once translocated from the symbiont to the host, we therefore presume that ${ }^{13} \mathrm{C}$ is incorporated into host biomass such as proteins and lipids through the Golgi apparatus
(Boncompain and Perez, 2013). Overall, carbon assimilation into the host seems to be different in Collodaria-Brandtodinium symbiosis compared to other dinoflagellate photosymbioses in corals (Symbiodiniaceae) and foraminifera (Pelagodinium) (Kopp et al., 2015; Lekieffre et al., 2018). In these symbioses, ${ }^{13} \mathrm{C}$ enrichment was first observed in the host lipid droplets after $2 \mathrm{~h}$ and later elsewhere in the host cell. In our study, no putative lipid droplets were observed in collodarian hosts in different sections imaged with electron microscopy, which may explain the ${ }^{13} \mathrm{C}$ assimilation differences compared to other photosymbioses. We may also consider that most 
of the carbon fixed and stored by the symbionts during the day could be transferred overnight to its host, thereby explaining low ${ }^{13} \mathrm{C}$ fraction in the host in the experimental setup of this study. One analytical aspect to take into account is that NanoSIMS provides 2D information so depending on the cellular sections, some important organelles can be missed in the imaging areas, such as lipid droplets or vacuoles. In the matrix of the colony, the extracellular vacuoles observed with $3 \mathrm{D}$ electron microscopy (Fig. 3E-I) that are potentially a route for metabolic exchanges were not showing carbon assimilation activity. This may be explained by the fact that soluble photosynthates (sugars), which are transferred to hosts in photosymbioses (Davy et al., 2012), are lost during sample preparation, and could not be visualized with nanoSIMS (Loussert-Fonta et al., 2020).

The subcellular natural abundance of nitrogen $\left({ }^{12} \mathrm{C}^{14} \mathrm{~N}^{-} /{ }^{12} \mathrm{C}_{2}{ }^{-}\right.$; without ${ }^{15} \mathrm{~N}$ labelling), which is limiting in the ocean (Geider and La Roche, 2002; Moore et al., 2013), showed that the microalgae Brandtodinium contained a significant amount of nitrogen $(\mathrm{N})$ in plastids, pyrenoids and nucleus (Fig. S6; Table S3). The N-rich photosynthetic machinery is due to the high concentration of photosystems and pigments in the plastid and the $\mathrm{CO}_{2}$ fixing Rubisco in the pyrenoid. In the nucleus, the chromosomes and the nucleolus were particularly rich in $\mathrm{N}$, likely representing ribosomes and proteins associated to the chromatin [e.g. histone-like (Gornik et al., 2019)] (Fig. S6). Overall, subcellular mapping of natural nitrogen pinpointed metabolic needs of the symbiotic microalgae and suggests that the host may provide $\mathrm{N}$ to support the functioning of the nucleus and photosynthetic machinery. Collodaria are known to be active predators (Swanberg and Caron, 1991), therefore representing a source of nitrogen for their symbionts. In addition, like benthic and other planktonic hosts (Rädecker et al., 2015; LeKieffre et al., 2020), we presume that collodarians can uptake inorganic nitrogen such as ammonium and transfer it to its symbionts, but this remains unknown.

In order to reveal the first steps of $\mathrm{N}$ flux between the two partners, symbiotic associations were incubated with ${ }^{15} \mathrm{~N}$-labelled ammonium for $3 \mathrm{~h}$. A high ${ }^{15} \mathrm{~N}$ fraction was measured in small hotspots in the algal cell from both colonies: up to $3.1 \pm 0.8$ atom\% which correspond to $2.9 \pm 0.9$ atom\% of relative $\mathrm{N}$ assimilation (Ka). These ${ }^{15} \mathrm{~N}$ hotspots correspond to crystalline inclusions as seen by electron microscopy (Figs 1E, 3A, 4J). FIB-SEM reconstruction showed that, in the symbiotic stage, N-rich crystals were located at the cell periphery and can represent c. $2 \%$ of the algal cell volume (Fig. 4). Based on their morphologies in EM, these crystals likely correspond to the purines guanine or uric acid, which are known to be nitrogenous reserves in microalgae including the symbiotic Symbiodiniaceae in corals (Clode et al., 2009; Kopp et al., 2013; Mojzeš et al., 2020). Note that we did not observe these crystals in the free-living microalgae, which may be explained by the fact that they grow in an N-replete culture medium so do not need to store $\mathrm{N}$. These crystals showed close physical contacts with the plastids and pyrenoids (Fig. $3 \mathrm{~A}$ ), indicating that these organelles may either produce or benefit from this $\mathrm{N}$ reserve. The presence of purine crystals would ensure $\mathrm{N}$ availability in $\mathrm{N}$-depleted waters or when prey feeding by the host is restricted. Future studies are required to better understand the dynamics of this $\mathrm{N}$ reserve in symbiotic microalgae over $24 \mathrm{~h}$ and in different trophic conditions (e.g. hosts in starved or N-replete conditions).

The ${ }^{15} \mathrm{~N}$ fraction was also important in the nucleolus of the algal nucleus $(2.9$ atom $\% \pm 0.3$ or 2.7 atom $\% \pm 0.3$ $\mathrm{Ka}$ ). This suggests that $\mathrm{N}$ is preferentially utilized and allocated for the synthesis of ribosomes inside the $\mathrm{N}$-rich nuclear apparatus. Euchromatin was also ${ }^{15} \mathrm{~N}$-enriched $(1.6$ atom\% $\mathrm{Ka})$ and similar $\mathrm{Ka}$ values were found in the condensed chromatin, plastid and pyrenoid (c. 0.6 atom\% Ka) (Fig. 4). In addition to N, subcellular mapping of natural phosphorous $\left({ }^{31} \mathrm{P} /{ }^{12} \mathrm{C}_{2}\right)$ showed that the nucleus of Brandtodinium is the organelle that contains the most $P$ in the algal cell, more specifically in the condensed chromatin with up to $c$. 10 times more than in other organelles (Fig. S6; Table S3).

In the host cell, a low ${ }^{15} \mathrm{~N}$ fraction was found $(0.76 \pm 0.05$ atom\%; Ka: $0.40 \pm 0.05$ atom\%) in the Golgi apparatus, including cisternae and secretory vesicles (Fig. 4 and Fig. S5). Whether this ${ }^{15} \mathrm{~N}$ originates from a direct ammonium assimilation by the host cell or from $\mathrm{N}$ exchanges with the symbiotic dinoflagellates cannot be resolved in this study and would require shorter incubations (e.g. $<1$ h). Overall, ${ }^{15} \mathrm{~N}$-assimilation in the collodarian host cell seems to be slower compared to other protistan photosymbioses. For example, in foraminiferal symbiosis, ${ }^{15} \mathrm{~N}$-enrichment in the host cell was detected in specific structures already after $1 \mathrm{~h}$ of incubation with ${ }^{15} \mathrm{~N}$-ammonium and rapidly spread to the entire host cell (LeKieffre et al., 2020).

\section{Subcellular distribution of sulfur in symbiotic cells}

Sulfur plays a pivotal role as antioxidant protection with the production of several compounds, such as dimethylsulfoniopropionate (DMSP), which is implied in photosymbiosis and contribute to the global sulfur cycle of the ocean (Simó, 2001; Giordano et al., 2005; Raina et al., 2010; Decelle et al., 2012; Gutierrez-Rodriguez et al., 2017). Here, we visualized sulfur distribution in cells to bring new insights into the metabolism and homeostasis of this element in photosymbiosis. Quantification using Synchrotron X-Ray Fluorescence (S-XRF) imaging revealed that symbiotic microalgae contained 
around two times more sulfur than their host Collodaria (Fig. 5; Table S4). Similar subcellular distribution and concentrations were found between symbiotic (mean $\pm \mathrm{SD}=2400 \mathrm{ppm} \pm 600 ; n=13$ ) and free-living (mean $\pm \mathrm{SD}=2100 \mathrm{ppm} \pm 400 ; n=33$ ) Brandtodinium cells. NanoSIMS showed that sulfur was mostly located in the condensed chromatin, and then about two times less in pyrenoids and plastids in descending order (Fig. 5; Table S4). This is in contrast to what is known in other microalgae where most sulfur is contained in the photosynthetic machinery (Giordano et al., 2005; Decelle et al., 2019). In addition, in the symbiotic microalgae, nanoSIMS revealed a large vacuole of $2.7 \mu \mathrm{m}$ in size, which contained much more sulfur than chromatin (Figs 1, 2 and 5). FIB-SEM reconstruction showed that this vacuole can represent up to $7 \%$ of the algal cell volume (Fig. 2). This vacuole did not assimilate ${ }^{13} \mathrm{C}$ and ${ }^{15} \mathrm{~N}$ and contained no phosphorous (Fig. 6 and Fig. S6). It is known that Brandtodinium in symbiosis can produce 100-fold higher DMSP compared to the free-living form (Gutierrez-Rodriguez et al., 2017). Therefore, this S-rich vacuole could contain DMSP and DMS as also observed in Symbiodiniaceae in culture (Raina et al., 2017) or other S-rich molecules involved in the algal metabolism. Of note, in the matrix of the host Collodaria, sulfur was also highly concentrated (5400 ppm \pm 800$)$ in the numerous extracellular vacuoles reconstructed in 3D above (Figs 3 and 5, Table S4). These vacuoles contained four and two times more sulfur than in the host endoplasm and symbiont respectively. This would indicate that sulfur-
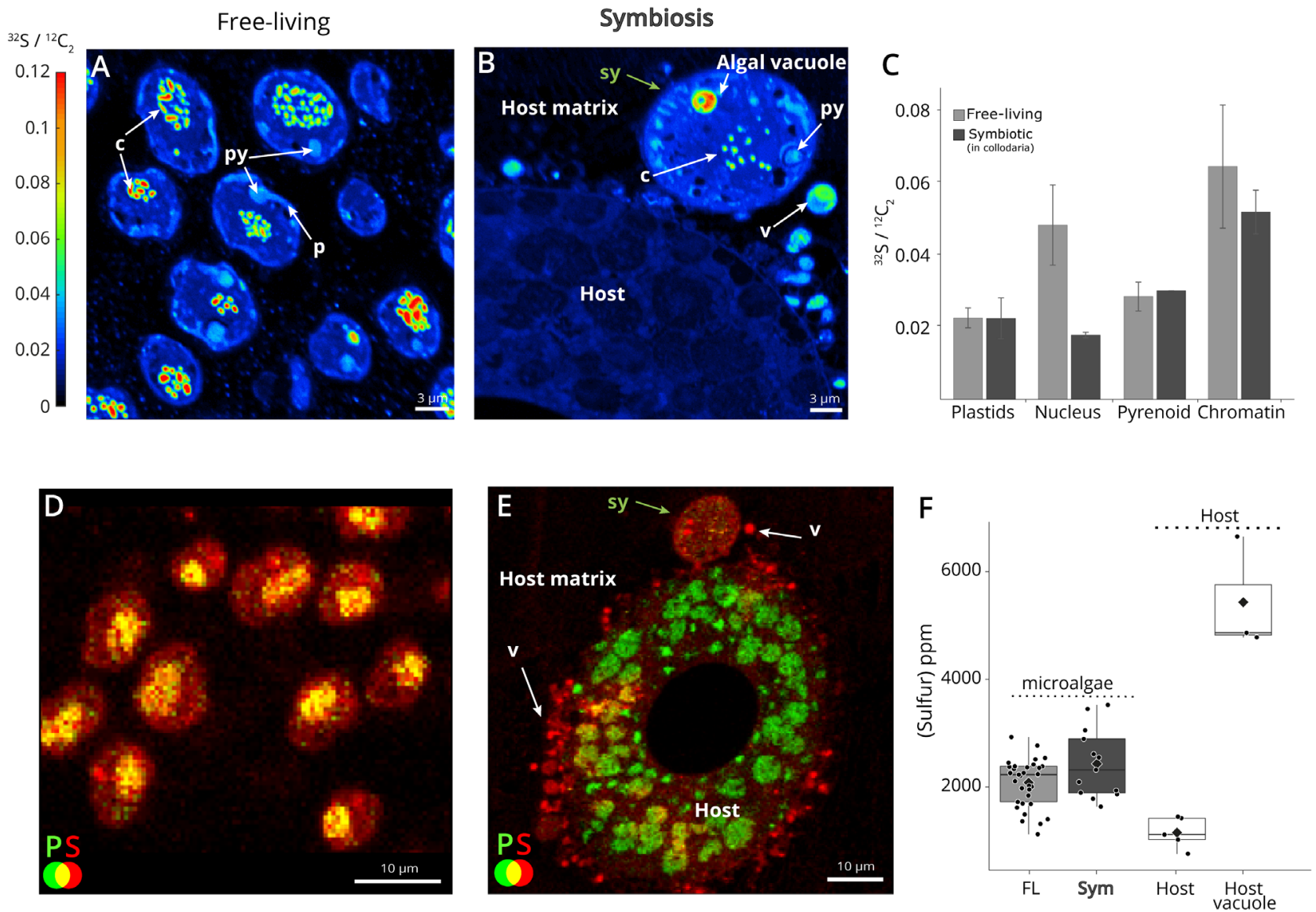

Fig. 5. Subcellular distribution of sulfur in the collodaria photosymbiosis unveiled by nanoSIMS and synchrotron X-ray fluorescence (S-XRF). $\mathrm{A}$ and $\mathrm{B}$. Sulfur $\left({ }^{32} \mathrm{~S} /{ }^{12} \mathrm{C}_{2}\right)$ mapping in free-living $(\mathrm{A})$ and symbiotic $(\mathrm{B})$ microalgae unveiled by nanoSIMS. Sulfur was mainly localized in chromatin of microalgae, but also in a large vacuole in the symbiotic cell (green arrow in B). Sulfur was also concentrated in vacuoles of the matrix between the host cell and the symbiotic microalga. Scale size: $3 \mu \mathrm{m}$.

C. Normalized sulfur content $\left({ }^{32} \mathrm{~S} /{ }^{12} \mathrm{C}_{2}\right)$ measured by nanoSIMS in different organelles (plastids, nucleus, pyrenoid and chromatin) of free-living (light grey) and symbiotic (dark grey) microalgae (Table S3).

$\mathrm{D}$ and E. Sulfur (red) and phosphorous (green) distribution unveiled by S-XRF imaging showing high concentration of sulfur in microalgae (plastids, chromatin) and the vacuoles of the matrix. The co-localization of $S$ and $P$ is indicated by the yellow colour (nucleus of the microalgae in $D$ ). F. Sulfur concentration (ppm) measured by S-XRF in the free-living $(n=33)$ and symbiotic Brandtodinium $(n=13)$ cells (dark and light grey respectively), as well as in the host cell $(n=5)$ and the vacuoles of the matrix. (n: nucleus; c: condensed chromatin; py: pyrenoid; p: plastid; $h$ : host cell (Collodaria); m: matrix; v: vacuoles in the matrix). [Color figure can be viewed at wileyonlinelibrary.com] 

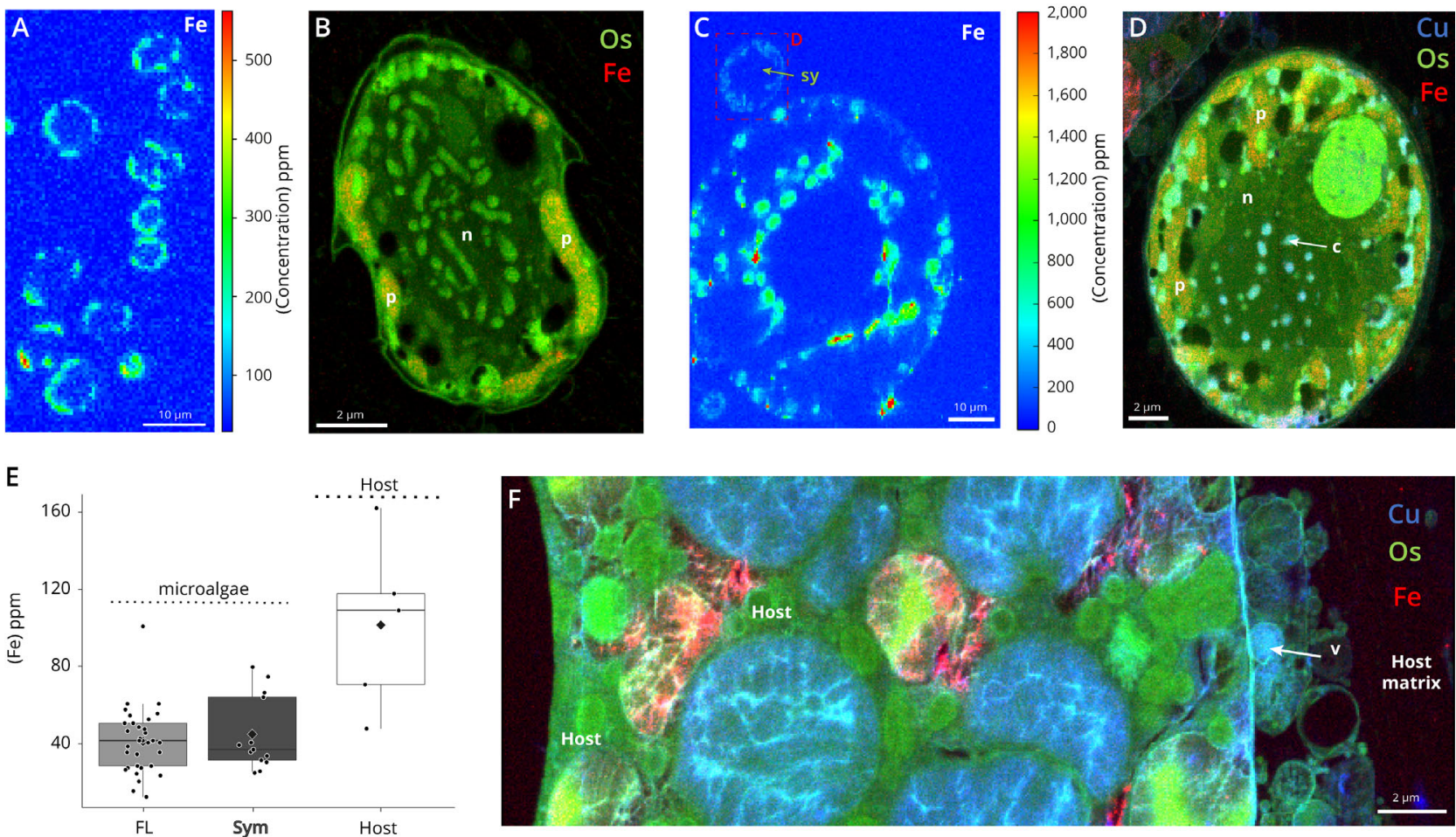

Fig. 6. Concentration and subcellular distribution of the trace metals iron $(\mathrm{Fe})$ and copper $(\mathrm{Cu})$ in microalgal and host cells unveiled by synchrotron X-ray fluorescence.

A, C. Subcellular quantitative mapping of iron ( $\mathrm{Fe})$ showing its concentration $(\mathrm{ppm})$ in free-living microalgae $(\mathrm{A})$, and in a host and its symbiotic microalga (C) $(500 \mathrm{~nm}$ lateral resolution and at $7.3 \mathrm{keV})$. Scale bar: $10 \mu \mathrm{m}$.

$\mathrm{B}, \mathrm{D}$ and $\mathrm{F}$. High-resolution mapping ( $50 \mathrm{~nm}$ lateral resolution and at $17.5 \mathrm{keV}$ ) of osmium (Os, green, providing ultrastructure information), iron (Fe, red) and copper (Cu, blue) in free-living (B) and symbiotic (D) microalgae, and in the host cell (F) extracted from XRF hyperspectral images. Scale bars: $2 \mu \mathrm{m}$. Fe was mainly concentrated in plastids and host vacuoles. Note that $\mathrm{Cu}$ was only detected in symbiotic microalgae in the condensed chromatin (c) and cytoplasmic vacuoles, and was below the detection limit in free-living cells (see also Fig. S8).

E. Intracellular iron concentration (ppm) measured by S-XRF in the free-living (FL; $n=33$ ) and symbiotic Brandtodinium (Symb, $n=13$ ) cells (dark and light grey respectively), as well as in the host cell $(n=5)$. (n: nucleus; c: condensed chromatin; py: pyrenoid; p: plastid; h: host cell (Collodaria); m: matrix; v: vacuoles in the matrix). [Color figure can be viewed at wileyonlinelibrary.com]

containing molecules and/or proteins could be exchanged between both partners, thus stressing the role of the sulfur metabolism in photosymbiosis. Future analyses using complementary mass spectrometry imaging (e.g. ToF-SIMS) should be conducted to identify the $S$ compounds in symbiotic cells at relatively high resolution $(<1 \mu \mathrm{m})$ (Passarelli et al., 2017; Raina et al., 2017).

\section{Subcellular mapping of metals in symbiotic cells}

Trace metals are essential for diverse biochemical functions, such as photosynthesis, antioxidant and photoprotection (Morel and Price, 2003; Twining and Baines, 2013). The ecological success of photosymbiosis in oceanic waters must therefore rely on efficient mechanisms to uptake and regulate the exchange of these elements. More particularly, iron $(\mathrm{Fe})$ has been shown to be pivotal for the physiology and health of coral photosymbioses (Reich, 2020). Yet, trace metal contents in planktonic photosymbioses remain largely unexplored, and their visualization and quantification in cells can provide information not only on the functioning of photosymbiosis but also of the impact in trace element cycling, especially because collodarians are important agents in vertical flux of organic matter (Guidi et al., 2016).

In collodarian colonies (including the symbiotic microalgae), metallome analyses showed that $\mathrm{Mn}, \mathrm{Fe}, \mathrm{Zn}$ and $\mathrm{Ni}$ were the main trace metals (intracellular metal quotas normalized against phosphorus as the biomass indicator: ranging from 10 to $30 \mathrm{mmol} \mathrm{mol}^{-1} \mathrm{P}$ ), while $\mathrm{Co}$ and $\mathrm{Cu}$ were measured in relatively lower concentration (from 0.1 to $20 \mathrm{mmol} \mathrm{mol}^{-1}$ P) (Fig. S7; Table S5). We can note that Fe quota is about three times more than that of zooplankton (4.6 and $4.9 \mathrm{mmol} \mathrm{Fe} / \mathrm{mol} \mathrm{P}$ ) and phytoplankton (5.2 and $4.7 \mathrm{mmol} \mathrm{Fe} / \mathrm{mol} \mathrm{P}$ ) communities sampled in different oceanic regions (Twining and Baines, 2013). In other words, one collodarian colony of several millimetres long can contain 100-300 ng of Fe.

Two S-XRF beam lines were used to visualize and quantify $\mathrm{Fe}$ in cells at 500 and $50 \mathrm{~nm}$ spatial resolution 
with a beam energy of 7.3 and $17.5 \mathrm{keV}$ respectively. In the host, Fe concentration tended to be twofold higher (mean $\pm \mathrm{SD}=100 \pm 40 \mathrm{ppm} ; n=5$ ) than $\mathrm{Fe}$ in their symbiotic microalgae (mean $\pm \mathrm{SD}=45 \pm 18 \mathrm{ppm}$; $n=13$ ) (Fig. 6). More specifically, the host cytoplasm exhibited round structures with high concentration of $\mathrm{Fe}$ (c. 400 ppm). In microalgae, Fe was mainly concentrated in plastids and its concentration tended to be similar between free-living (42 $\pm 16 \mathrm{ppm} ; n=33$ ) and symbiotic cells ( $45 \pm 18 \mathrm{ppm} ; n=13$ ) (Fig. 6B). Yet, the comparison is difficult between free-living and symbiotic microalgae, which grow in Fe-replete culture medium $(5.85 \mu \mathrm{M})$ and in the host cell respectively. Nevertheless, the fact that microalgae seem to have similar Fe concentrations may indicate that the host could provide a Fereplete microhabitat for its symbionts. It is known that the dinoflagellates Symbiodiniaceae increase their intracellular $\mathrm{Fe}$ concentration as the external $\mathrm{Fe}$ concentration increases (Rodriguez et al., 2016; Reich, 2020).

Using high-resolution and high-energy S-XRF beam line, copper $(\mathrm{Cu})$ was also detected and its distribution mapped in cells. Of note, $\mathrm{Cu}$ was only detected in the symbiotic stage of the microalga but not in free-living (below the detection level) (Fig. 6 and Fig. S8). More specifically, within the cell, $\mathrm{Cu}$ was highly concentrated (6900 ppm) in the condensed DNA chromatin and vacuoles physically associated to plastids. In the host, $\mathrm{Cu}$ was present in large round structures and in some small vacuoles of the matrix (1900 ppm) (Fig. 6), which, like sulfur, may reflect the exchange of this metal between the host and the symbionts. The increase of $\mathrm{Cu}$ concentration in symbiotic microalgae represents a symbiotic fingerprint and stresses the influence of the host on their metal homeostasis. It is known that $\mathrm{Cu}$ is needed in the electron transport chain of the plastid (plastocyanin) and mitochondria (cytochrome $c$ oxidase) and is a key cofactor in many proteins (Morel et al., 2003), but this study cannot resolve the function of this metal in the symbiosis. Nevertheless, $\mathrm{Cu}$ is known to be toxic at very low concentration (Morel and Price, 2003), to induce ROS production and DNA damage and is implicated in various neurological disorders, implying that its exchange between symbiotic partners should be highly regulated. Overall, the subcellular mapping of trace metals calls for more studies on the role of these metals in the symbiotic interaction. Because collodaria are significant contributors to the vertical flux in the ocean (Biard et al., 2016), these results also stress the role of photosymbiosis in the biogeochemical cycles of trace metals.

\section{Conclusions}

The aim of this study was to improve our understanding on the functioning and metabolism of the uncultivated yet ubiquitous oceanic photosymbiosis between Collodaria and its symbiotic microalgae Brandtodinium using multimodal subcellular imaging. We showed that the volume occupancy of the plastid and C-fixing pyrenoid of the microalga was higher in symbiosis and was accompanied by a higher photosynthetic performance at high light. By contrast, the topology and volume of the mitochondria were similar, suggesting similar respiration rate in freeliving and symbiotic microalgae. The enlargement of the photosynthetic apparatus seems to be a morphological trait in planktonic photosymbiosis as it was also found in other radiolarians (Acantharia) living with the microalga Phaeocystis (Decelle et al., 2019; Uwizeye et al., 2021b). Yet, the expansion of the photosynthetic machinery observed here in Brandtodinum is less substantial than in Phaeocystis, which can increase by 100 -fold the volume of total plastids (Uwizeye et al., 2021b). This may be explained by the level of integration and growth of the microalgal cell within its host. In Collodaria, symbiotic microalgae are outside the host endoplasm in the gelatinous matrix, can divide [possibly at lower rate than freeliving cells in culture like in coral photosymbioses (Davy et al., 2012)] and they are not associated to a single host cell but can freely move within the greenhouse-like colony interacting with several host cells over time. By contrast, the level of integration and host control is higher in Acantharia since the microalga Phaeocystis is constrained within the endoplasm of its host and its cell division is blocked but plastids continue to divide producing a highly voluminous algal cell. This indicates that radiolarian hosts have different strategies to control and accommodate their symbiotic microalgae. Note that the comparison between free-living and symbiotic microalgae in this study cannot provide a complete understanding of the metabolism and physiology of symbiotic microalgae in their host. The different nutrient and light conditions and potentially cell growth in both life stages could be confounding variables. Therefore, future studies should use new techniques and methods to strengthen the comparison between ex hospite and in hospite lifestyles (Maruyama and Weis, 2021). Manipulation of the freeliving stage (e.g. different nutritional conditions) or harvesting cultured microalgae at different growth phases (e.g. stationary phase) could be considered to better understand the metabolic and morphological flexibility of the microalgal cell.

Based on 3D electron microscopy and chemical imaging, we suggest that the metabolic connection between partners in Collodaria between partners occurs through numerous extracellular vacuoles in the matrix, which contained nutrients, such as nitrogen, sulfur and copper. These nutrients are therefore important for the functioning of the symbiosis and future analyses are required to identify the underlying metabolites. We demonstrated that 
carbon and nitrogen were stored by the symbiotic microalgae during the day and transferred in low amount in the Golgi apparatus of the host. This transfer seems to be less efficient than other planktonic and benthic photosymbioses (Kopp et al., 2013; LeKieffre et al., 2020), presumably due to the loose interaction between the symbionts and the host cells. Dynamic nutrient exchange at different time points during day and night periods should be carried out in future stable isotope labelling studies to fully understand the metabolic connection and flux of nutrients in this ecologically successful photosymbiosis. Overall, the visualization of the morphology and metabolism of this symbiosis at the nanoscale calls for more studies to better assess the importance of Collodaria in the biogeochemical cycles of carbon, sulfur and metals in the ocean.

\section{Experimental procedures}

Sampling and isolation of collodaria and microalgae

Colonies of collodarians (radiolarians) were gently collected at the subsurface in the Mediterranean Sea (Villefranche-sur-Mer, France) using a plankton net of $150 \mu \mathrm{m}$ in mesh size. Live collodarians (Collozoum spp. from the family Sphaerozoidae) were then isolated through the binocular, maintained in filtered seawater and controlled light and temperature conditions, and cryofixed with high pressure freezing to preserve the native ultrastructure and chemistry of cells (Moore et al., 2012; Kashiv et al., 2016; Decelle et al., 2020). In parallel, the microalgae [the dinoflagellate $B$. nutricula RCC 3387 ; isolated from Collodaria in Villefranche-sur-Mer (Probert et al., 2014)] grown in culture medium K2 (http://roscoffculture-collection.org/culture-media) at $20^{\circ} \mathrm{C}$ were also cryofixed in the exponential phase in the same conditions. Time-lapse video using an inverted microscope was conducted on live colonies upon collection during several hours with image capture every $20 \mathrm{~s}$. Trajectory of symbiotic microalgae over time was reconstructed with the plugin Particle Tracker for Fiji (Sbalzarini and Koumoutsakos, 2005).

\section{Photophysiology}

Photosynthetic activity was imaged with a fluorescence imaging setup described in Decelle et al. (2019). The photosynthetic ETR was calculated as the product of the light intensity times the photochemical yield in the light: PFD $\left.\times\left(F_{\mathrm{m}}{ }^{\prime}-F\right) / F_{\mathrm{m}}{ }^{\prime}\right)$, where $F$ and $F_{\mathrm{m}}{ }^{\prime}$ are the steadystate and maximum fluorescence intensities in lightacclimated cells respectively, and photosynthetic flux density (PFD) is the light irradiance in $\mu \mathrm{mol}$ quanta $\times \mathrm{m}^{-2} \mathrm{~s}^{-1}$. The light intensity was increased stepwise from 29 to $1200 \mu \mathrm{mol}$ quanta $\times \mathrm{m}^{-2} \mathrm{~s}^{-1}$. The photoprotective responses were evaluated by measuring the NPQ of fluorescence (Maxwell and Johnson, 2000) using the fluorescence setup described above. The NPQ was calculated as $1-\left(F_{\mathrm{m}}{ }^{\prime} / F_{\mathrm{m}}\right)$. The $F_{\mathrm{v}} / F_{\mathrm{m}}$ parameter (maximum potential quantum efficiency of Photosystem II) was assessed as $F_{\mathrm{m}}-F_{\mathrm{o}} / F_{\mathrm{m}}$ where $F_{\mathrm{m}}$ and $F_{0}$ are the maximum and minimum fluorescence intensities. This parameter was also measured on single symbiont cells using a homemade fluorescence imaging setup. The system uses a high sensitivity camera (Orca Flash 4.0 LT, Hamamatsu, Japan) equipped with a near-infrared longpass filter (RG 695 Schott, Germany), mounted on an optical microscope (CKX 53 Olympus, Japan). Fluorescence was measured upon excitation with short pulses (duration $260 \mu \mathrm{s}$ ) of blue light $(\lambda=470 \mathrm{~nm} \pm 12 \mathrm{~nm}$ ), and green LEDs were used to generate short saturating pulses (intensity $3000 \mu \mathrm{mol}$ photons $\mathrm{m}^{-2} \mathrm{~s}^{-1}$, duration $250 \mathrm{~ms}$ ) to induce the maximum fluorescence $F_{\mathrm{m}}$. The blue and green LEDs were mounted on an array located on the upper part of the microscope, i.e. opposite to the objectives used for detection. We used a $20 \times$ (numerical aperture $=0.45$ ) objective to scan the slits in the transmission mode.

\section{Sample preparation for electron microscopy and chemical imaging}

Rapid freezing methods are universally accepted as superior to chemical fixation in preserving cell ultrastructure and chemistry (Decelle et al., 2020). Symbiotic collodarians (host and algal symbionts) and free-living microalgae (previously centrifugated at $3000 \mathrm{~g}$ for $2 \mathrm{~min}$ ) were therefore cryo-fixed in seawater as in Decelle et al. (2019), using high-pressure freezing (HPM100, Leica) where cells were subjected to a pressure of $210 \mathrm{MPa}$ at $-196^{\circ} \mathrm{C}$ for $30 \mathrm{~ms}$, followed by freeze substitution (FS) (EM ASF2, Leica). For the FS, a mixture 2\% (wt./vol.) osmium tetroxide and $0.5 \%$ (wt./vol.) uranyl acetate in dried acetone was used. The FS machine was programmed as follows: $60-80 \mathrm{~h}$ at $-90^{\circ} \mathrm{C}$, heating rate of $2^{\circ} \mathrm{C} \mathrm{h}^{-1}$ to $-60^{\circ} \mathrm{C}(15 \mathrm{~h}), 10-12 \mathrm{~h}$ at $-60^{\circ} \mathrm{C}$, heating rate of $2^{\circ} \mathrm{C} \mathrm{h}^{-1}$ to $-30^{\circ} \mathrm{C}(15 \mathrm{~h}), 10-12 \mathrm{~h}$ at $-30^{\circ} \mathrm{C}$. Samples were then washed in acetone four times for $20 \mathrm{~min}$ at $-30^{\circ} \mathrm{C}$ and embedded in anhydrous araldite. Without accelerator, a graded resin/acetone (vol./vol.) series was used $(30 \%, 50 \%$ and $70 \%$ resin) with each step lasting $2 \mathrm{~h}$ at increased temperature: $30 \%$ resin/acetone bath from $-30^{\circ} \mathrm{C}$ to $-10^{\circ} \mathrm{C}, 50 \%$ resin/acetone bath from $-10^{\circ} \mathrm{C}$ to $10^{\circ} \mathrm{C}, 70 \%$ resin/acetone bath from $10^{\circ} \mathrm{C}$ to $20^{\circ} \mathrm{C}$. Samples were then placed in $100 \%$ resin without accelerator for $8-10 \mathrm{~h}$ and in $100 \%$ resin with accelerator (BDMA) for $8 \mathrm{~h}$ at room temperature. Prior to ultra-sectioning, symbiotic cells were observed in the resin block 
to define the trimming region and the $z$-position of cells in the block. Trimming around the targeted cells was performed with razor blades and the EM Trimming Leica machine. Thin sections $(200-400 \mathrm{~nm}$ thick) were then obtained using an ultramicrotome (Leica EM) with ultradiamond knife (Diatom) and placed on 10-mm arsenicdoped silicon wafers for NanoSIMS, and on $\mathrm{Si}_{3} \mathrm{~N}_{4}$ membrane windows for synchrotron $\mathrm{X}$-rays fluorescence. Adjacent sections of $60-80 \mathrm{~nm}$ thick were also obtained for TEM analysis.

\section{FIB-SEM acquisition and analysis}

For FIB-SEM, upon high-pressure freezing, the cocktail of the freeze substitution contained $2 \%$ (wt./vol.) osmium tetroxide and $0.5 \%$ (wt./vol.) uranyl acetate in dried acetone as in Uwizeye et al. (2021a, 2021b). The cells were washed four times in anhydrous acetone for $15 \mathrm{~min}$ each at $-30^{\circ} \mathrm{C}$ and gradually embedded in anhydrous araldite resin. The sample was trimmed with a $90^{\circ}$ diamond knife (Diatome) to expose the cells at two surfaces (the imaging surface and the surface perpendicular to the FIB) and optimize the acquisition (Maco et al., 2014). When targeting the symbiotic microalgae within its host, the trimming was targeted towards the periphery of the organisms where they were in higher numbers. After the sample was trimmed, it was mounted onto the edge of an SEM stub (Agar Scientific) using silver conductive epoxy (CircuitWorks) with the trimmed surfaces facing up and towards the edge of the stub. The sample was gold sputter coated (Quorum Q150RS; $180 \mathrm{~s}$ at $30 \mathrm{~mA}$ ) and placed into the FIB-SEM for acquisition (Crossbeam 540, Carl Zeiss Microscopy GmbH). Once the region of interest (ROI) was located in the sample, Atlas3D software (Fibics and Carl Zeiss Microscopy $\mathrm{GmbH}$ ) was used to perform sample preparation and $3 \mathrm{D}$ acquisitions. First, a $1 \mu \mathrm{m}$ platinum protective coat $\left(20-30 \mu \mathrm{m}^{2}\right.$ depending on ROI) was deposited with a $1.5 \mathrm{nA}$ FIB current. The rough trench was then milled to expose the imaging cross-section with a $15 \mathrm{nA}$ FIB current, followed by a polish at $7 \mathrm{nA}$. The 3D acquisition milling was done with a $1.5 \mathrm{nA}$ FIB current. For SEM imaging, the beam was operated at $1.5 \mathrm{kV} / 700 \mathrm{pA}$ in analytic mode using an EsB detector ( $1.1 \mathrm{kV}$ collector voltage) at a dwell time of $8 \mu \mathrm{s}$ with no line averaging. For each slice, a thickness of $8 \mathrm{~nm}$ was removed, and the SEM images were recorded with a pixel size of $8 \mathrm{~nm}$, providing an isotropic voxel size of $8 \times 8 \times 8 \mathrm{~nm}^{3}$. Whole volumes were imaged with 1000-1200 frames, depending on the Brandtodinium cells. Raw electron microscopy data are deposited in EMPIAR, accession code EMPIAR-47483651. Source data are provided with this article.

The first step of image processing was to crop the freeliving and symbiotic Brandtodinium cells using the open software Fiji (https://imagej.net/Fiji), followed by image registration (stack alignment), noise reduction, semi-automatic segmentation, 3D reconstruction of microalgae cells and morphometric analysis as in (Uwizeye et al., 2021a). Image registration was done by the FIJI plugin 'Linear Stack Alignment with SIFT' (Lowe, 2004), then fine-tuned by AMST (Hennies et al., 2020). Aligned image stacks were filtered to remove noise and highlight contours using a Mean filter in Fiji (0.5 pixel radius). Segmentation of organelles and other cellular compartments of Brandtodinium and Collodaria was carried out with 3D Slicer software (Kikinis et al., 2014) (www.slicer.org), using a manually curated, semi-automatic pixel clustering mode (5-10 slices are segmented simultaneously in z) as in Uwizeye et al. (2021a). We assigned colours to segmented regions using paint tools and adjusted the threshold range for image intensity values. Morphometric analyses were performed with the 3D slicer module 'segmentStatistics' on the different segments (segmented organelles) and converted to $\mu \mathrm{m}^{3}$ or $\mu \mathrm{m}^{2}$ taking into account the voxel size of $8 \mathrm{~nm}$ (Table S1).

\section{Synchrotron X-ray fluorescence imaging}

S-XRF hyperspectral images were acquired on the ID21 and ID16B-NA beamlines of the European Synchrotron Radiation Facility (Cotte et al., 2017, Martinez-Criado et al. 2016). $300 \mathrm{~nm}$-thick cell sections were laid on $\mathrm{Si}_{3} \mathrm{~N}_{4}$ membranes. On ID21 the incoming $X$-rays were tuned to the energy of $7.3 \mathrm{keV}$ with a fixed-exit double crystal $\mathrm{Si}$ (111) monochromator, and focused to $0.3 \times 0.8 \mu \mathrm{m}^{2}$ with a Kirkpatrick-Baez (KB) mirror system, yielding a flux of $5 \times 10^{10} \mathrm{ph} \mathrm{s}^{-1}$. The experiment was performed under vacuum $\left(10^{-5}-10^{-4} \mathrm{mbar}\right)$. The emitted fluorescence signal was detected with energy dispersive, large area $\left(80 \mathrm{~mm}^{2}\right)$ SDD detectors equipped with a Be window (SGX from RaySpec). Images were acquired by rasterscanning the sample in the X-ray focal plane, with a $0.5 \times 0.5 \mu \mathrm{m}^{2}$ step and $500 \mathrm{~ms}$ dwell time. The detector response was calibrated over a thin film reference sample consisting of layers of elements in $\mathrm{ng} \mathrm{mm}^{-2}$ concentration sputtered on a $200 \mathrm{~nm}$ thick $\mathrm{Si}_{3} \mathrm{~N}_{4}$ membrane (RF7-200-S2371 from AXO), measured using the same acquisition parameters.

On ID16B-NA, a beam of $17.5 \mathrm{keV}$ focused to $50 \times 50 \mathrm{~nm}^{2}$ through $\mathrm{KB}$ mirrors was used to excite the samples. The photon flux at sample was $\sim 2 \times 10^{11} \mathrm{ph} \mathrm{s}^{-1}$. High-resolution XRF images $\left(50 \times 50 \mathrm{~nm}^{2}\right.$ step size) were acquired in air, with a dwell time of $100 \mathrm{~ms} /$ pixel. Two 3-element SDD detector arrays were used to collect fluorescence from the sample. The detector response was calibrated over a thin film reference sample (RF8-200-S2453 from AXO). High-resolution images were acquired for free and symbiotic microalgae, and in selected areas of the hosts. 
Hyperspectral images acquired in both beamlines were normalized by the incoming photon flux and subjected to the same data analysis protocol. Elemental mass fractions were calculated from fundamental parameters with the PyMca software package (Solé et al., 2007), assuming a biological matrix of light elements $(\mathrm{H}, \mathrm{C}, \mathrm{N}, \mathrm{O})$ and a density of $1 \mathrm{~g} \mathrm{~cm}^{-3}$, as reported in the NIST Star database for the standard composition of soft tissue (https:// www.physics.nist.gov/cgi-bin/Star/compos.pl?matno=

261). The calculation of the elemental concentrations in specific areas was performed by manually selecting the pixels in the ROI and summing up their fluorescence signal; the sum spectrum normalized by the number of pixels was then subjected to spectral deconvolution, and the peak areas were converted in mass fractions (see also Table S4).

NanoSIMS mapping of $C, N, P$ and $S$ in samples of natural isotopic composition

The wafers containing thin sections were first coated with $20 \mathrm{~nm}$ gold-palladium and analysed with a NanoSIMS $50 \mathrm{~L}$ (Cameca, Gennevilliers, France), using 2 pA beam of $16 \mathrm{keV} \mathrm{Cs}^{+}$primary ions focused to $70 \mathrm{~nm}$ spot. The analysed sample area of $25 \times 25 \mu \mathrm{m}^{2}$ was scanned in $512 \times 512$ pixel raster with a dwelling time of $2 \mathrm{~ms} /$ pixel. Prior to the analysis, the area of $100 \times 100 \mu \mathrm{m}^{2}$ involving the analysis FoV was pre-implanted for $15 \mathrm{~min}$ with $200 \mathrm{pA} \mathrm{Cs}^{+}$beam to equilibrate the secondary ion yield. The data were acquired in 20-30 plains upon consecutive scanning with the primary ion beam. Secondary ions extracted from each pixel of the sample surface $\left({ }^{16} \mathrm{O}^{-}\right.$, ${ }^{12} \mathrm{C}_{2}{ }^{-},{ }^{12} \mathrm{C}^{13} \mathrm{C}^{-},{ }^{12} \mathrm{C}^{14} \mathrm{~N}^{-},{ }^{13} \mathrm{C}^{14} \mathrm{~N}^{-},{ }^{31} \mathrm{P}^{-}$and ${ }^{32} \mathrm{~S}^{-}$) were separated according to their mass to charge ratio $(\mathrm{m} / \mathrm{z})$ with mass resolving power above $8000(\mathrm{MRP}=\mathrm{M} / \mathrm{dR})$ achieved with $20 \times 140 \mu \mathrm{m}$ nominal size (width $\times$ height) of the entrance slit, $200 \times 200 \mu \mathrm{m}$ aperture, $40 \times 1800 \mu \mathrm{m}$ exit slits and the energy slit blocking $20 \%$ of ions at their high-energy distribution site. Complete $200 \mathrm{~nm}$ of section depth was consumed upon the analysis. The acquired data were evaluated using Look@nanoSIMS (LANS) software (Polerecky et al., 2012).

\section{${ }^{13} \mathrm{C}$ - and ${ }^{15} \mathrm{~N}$-labeling for TEM-NanoSIMS analysis}

Collodarians were collected at the subsurface in the Mediterranean Sea (Villefranche-sur-Mer, France) in September 2019. Live collodarians were then isolated under a binocular, transferred in $50 \mathrm{ml}$ plastic flasks filled with filtered $(0.22 \mu \mathrm{m})$ natural seawater (collected at the sea surface the same day). The day after the sampling, the incubation was initiated at $2 \mathrm{pm}$ under controlled light and temperature conditions $\left(20^{\circ} \mathrm{C}\right)$ by spiking with $\mathrm{H}^{13} \mathrm{CO}_{3}{ }^{-}$and ${ }^{15} \mathrm{NH}_{4}{ }^{+}(99 \%$, Sigma-Aldrich) to reach final concentrations of $2 \mathrm{mM}$ and
$10 \mu \mathrm{M}$ respectively. After $3 \mathrm{~h}$ of incubation, the experiment was stopped by removing the collodarian colonies from the spiked seawater and transferring them in filtrated seawater. The samples were then immediately cryofixed with highpressure freezing and processed as explained above. For correlated EM - NanoSIMS, ultrathin sections of 70 or $200 \mathrm{~nm}$ thick were obtained. The $70 \mathrm{~nm}$ sections were mounted onto copper grids or slots coated with a formvar carbon film. Sections were then stained in 1\% uranyl acetate (10 $\mathrm{min})$ and lead citrate (5 min). Micrographs were obtained using a Tecnai G2 Spirit BioTwin microscope (FEI) operating at $120 \mathrm{kV}$ with an Orius SC1000 CCD camera (Gatan). The $200 \mathrm{~nm}$ sections were mounted on silicon wafers and imaged with a GeminiSEM (Zeiss) operating in ESB mode at $3 \mathrm{kV}$. For NanoSIMS observations, sections were coated with $10 \mathrm{~nm}$ of gold and analysed with a NanoSIMS 50 I (Cameca, Lausanne, Switzerland), using a caesium $\left(\mathrm{Cs}^{+}\right)$primary ion beam with a current of about $2 \mathrm{pA}$ and an energy of $16 \mathrm{keV}$. The primary ion beam was focused to a nominal spot size of $\sim 120-150 \mathrm{~nm}$ and stepped over the sample in a $256 \times 256$ pixel raster to generate secondary ions with a dwelling time of $5 \mathrm{~ms} /$ pixel. The raster areas (scanning surface area) were defined based on previous SEM/TEM observations and were between $10 \times 10 \mu \mathrm{m}^{2}$ to $40 \times 40 \mu \mathrm{m}^{2}$. Secondary ions $\left({ }^{19} \mathrm{~F}^{-},{ }^{12} \mathrm{C}_{2}{ }^{-}\right.$, ${ }^{13} \mathrm{C}^{12} \mathrm{C}^{-},{ }^{12} \mathrm{C}^{14} \mathrm{~N}^{-},{ }^{12} \mathrm{C}^{15} \mathrm{~N}^{-},{ }^{31} \mathrm{P}^{-}$and ${ }^{32} \mathrm{~S}^{-}$) were simultaneously collected in electron multipliers at a mass resolution $(M / \Delta M)$ of about 8000 (Cameca definition). Each NanoSIMS image consists of $6-10$ sequential images, drift corrected and accumulated using the software LANS (Polerecky et al., 2012) to quantify mean ${ }^{13} \mathrm{C}$ and ${ }^{15} \mathrm{~N}$ enrichments of different sub-cellular structures. For control (i.e. not enriched) samples, four images were acquired including five symbiotic dinoflagellates and two different areas of the host cell (Table S2). These control images were used to determine the standard ratio against which the experimental ${ }^{13} \mathrm{C}$-and ${ }^{15} \mathrm{~N}$-enrichments were quantified. For ${ }^{13} \mathrm{C}$ and ${ }^{15} \mathrm{~N}$-enriched samples, two distinct collodarian colonies were analysed.

\section{Quantitation of assimilation activity}

The cellular activity in assimilation of carbon and nitrogen was derived from the detected changes in nitrogen and carbon isotopic composition. Changes in ${ }^{13} \mathrm{C}$ and ${ }^{15} \mathrm{~N}$ fractions are not directly proportional to cellular activity and the assimilation activity was therefore expressed as the relative assimilation $K_{A}^{i}$ (Stryhanyuk et al., 2018):

$$
K_{A}^{i}=\frac{R_{f}-R_{i}}{\left(1+R_{i}\right) \times\left\{D_{\mathrm{gs}} \times\left(1+R_{f}\right)-R_{f}\right\}}
$$

The $K_{A}^{i}$ represents the fraction (in at.\%) of carbon $\left({ }^{12} \mathrm{C}\right.$ and ${ }^{13} \mathrm{C}$ ) or nitrogen $\left({ }^{14} \mathrm{~N}\right.$ and $\left.{ }^{15} \mathrm{~N}\right)$ assimilated from a 
growth substrate into a biomass unit relatively to its initial content (carbon or nitrogen; before incubation with a labelled substrate) in a biomass unit, e.g. cell or cell fragment.

$$
K_{A}=\frac{D_{f}-D_{i}}{D_{\mathrm{gs}}-D_{f}}
$$

where $R_{i} / D_{i}$ is the initial isotope ratio/fraction in biomass unit (before incubation with isotope-labelled growth substrate); $R_{f} / D_{f}$ is the final isotope ratio/fraction in biomass unit (after incubation with isotope-labelled growth substrate) and $D_{\mathrm{gs}}$ is the fraction of heavy isotope in growth substrate.

\section{Bulk quantification of metals in collodaria (metallome)}

Free-living microalgae (Brandtodinium) in culture and collodarian colonies (single colonies and a mix of different colonies) collected in surface waters of the Mediterranean Sea were centrifugated to remove the medium and seawater respectively. Cells were then cryofixed and preserved at $-80^{\circ} \mathrm{C}$. For metal extraction, samples were dehydrated and mineralized in $200 \mu \mathrm{l} 65 \%$ (wt./vol.) ultrapure $\mathrm{HNO}_{3}$ at $90^{\circ} \mathrm{C}$ for $4 \mathrm{~h}$. Digested samples were diluted in distilled water and analysed using an ICAP RQ quadrupole mass instrument (Thermo Fisher Scientific $\mathrm{GmbH}$, Germany). The instrument was used with a MicroMist U-Series glass concentric nebulizer, a quartz spray chamber cooled at $3^{\circ} \mathrm{C}$, a Qnova quartz torch, a nickel sample cone and a nickel skimmer cone equipped with a high-sensitivity insert. Elements were analysed using either the standard mode (for ${ }^{27} \mathrm{Al},{ }^{31} \mathrm{P},{ }^{111} \mathrm{Cd}$ ) and/or the kinetic energy discrimination mode with helium as the collision cell gas (for ${ }^{31} \mathrm{P},{ }^{55} \mathrm{Mn},{ }^{56} \mathrm{Fe},{ }^{57} \mathrm{Fe},{ }^{58} \mathrm{Ni}$, $\left.{ }^{59} \mathrm{Co},{ }^{60} \mathrm{Ni},{ }^{63} \mathrm{Cu},{ }^{64} \mathrm{Zn},{ }^{65} \mathrm{Cu},{ }^{66} \mathrm{Zn}\right)$. Concentrations were determined using standard curves and corrected using an internal standard solution of 103Rh added online. Data integration was done using the Qtegra software (version 2.8.2944.115). Element content was normalized to phosphorus (P) content as in Twining and Baines (2013)) (see Table S5).

\section{Acknowledgements}

This research was supported by the Dept. of Isotope Biogeochemistry, Centre for Chemical Microscopy (ProVIS), Helmholtz Centre for Environmental Research (UFZ). We thank Estelle Bigeard and Fabien Lombard for sample collection and the institutes the Laboratoire d'Océanographie de Villefranche-sur-Mer (LOV) and the marine service crew. This research is also supported by EMBRC-France, whose French state funds are managed by the ANR within the Investments of the Future program under reference ANR10-INBS-02. This work used the platforms of the Grenoble
Instruct centre (ISBG; UMS 3518 CNRS-CEA-UJF-EMBL) with support from FRISBI (ANR-10-INSB-05-02) and GRAL (ANR-10-LABX-49-01) within the Grenoble Partnership for Structural Biology (PSB). We thank Guy Schoehn and Christine Moriscot, and the electron microscope facility, which is supported by the Rhône-Alpes Region, the Fondation Recherche Medicale (FRM), the fonds FEDER, the Centre National de la Recherche Scientifique (CNRS), the CEA, the University of Grenoble, EMBL and the GISInfrastructures en Biologie Sante et Agronomie (IBISA). The FIB-SEM work was done in collaboration with the electron microscopy core facility at EMBL Heidelberg. The authors acknowledge the support and the use of resources of Instruct, a Landmark ESFRI project. The authors acknowledge the ESRF for providing beamtime for this project (LS2625 and LS-2857 on ID16B-NA, in-house beamtime on ID21), and Marine Cotte and Hiram Castillo-Michel for their help in the experiments. We thank Louise Soegaard Jensen for access and help with SEM imaging, and Abby Ren, Stephane Escrig and Anders Meibom for NanoSIMS access and assistance. The authors are grateful to Dr. Lubos Polerecky (Utrecht University) for the continuous development of the LANS software, technical assistance and prompt implementation of software features.

\section{Author Contributions}

J.D. conceived and designed research, and drafted the manuscript; J.D., G.V., C.L., H.S., S.R., G.F. participated in data analysis, and helped draft and critically revised the manuscript. N.M., B.G., F.C., S.M., R.T., N.S., Y.S. contributed to data acquisition, culture collection, sample preparation and helped draft the manuscript. All authors gave final approval for publication and agree to be held accountable for the work performed therein.

\section{References}

Anderson, O.R. (1976) Ultrastructure of a colonial radiolarian Collozoum inerme and a cytochemical determination of the role of its zooxanthellae. Tissue Cell 8: 195-208.

Bhaud, Y., Guillebault, D., Lennon, J.F., Defacque, H., Soyer-Gobillard, M.O., and Moreau, H. (2000) Morphology and behaviour of dinoflagellate chromosomes during the cell cycle and mitosis. J Cell Sci 113: 1231-1239.

Biard, T., Bigeard, E., Audic, S., Poulain, J., GutierrezRodriguez, A., Pesant, S., et al. (2017) Biogeography and diversity of Collodaria (Radiolaria) in the global ocean. ISME J 11: 1331-1344.

Biard, T., Stemmann, L., Picheral, M., Mayot, N., Vandromme, P., Hauss, H., et al. (2016) In situ imaging reveals the biomass of giant protists in the global ocean. Nature 532: 504-507.

Blank, R.J. (1987) Cell architecture of the dinoflagellate Symbiodinium sp. inhabiting the Hawaiian stony coral Montipora verrucosa. Mar Biol 94: 143-155.

Boncompain, G., and Perez, F. (2013) The many routes of Golgi-dependent trafficking. Histochem Cell Biol 140: 251-260. 
Breitbarth, E., Wohlers, J., Kläs, J., LaRoche, J., and Peeken, I. (2008) Nitrogen fixation and growth rates of Trichodesmium IMS-101 as a function of light intensity. Mar Ecol Prog Ser 359: 25-36.

Cabello, A.M., Cornejo-Castillo, F.M., Raho, N., Blasco, D., Vidal, M., Audic, S., et al. (2016) Global distribution and vertical patterns of a prymnesiophyte-cyanobacteria obligate symbiosis. ISME J 10: 693-706.

Caron, D.A. (2016) Ocean science: the rise of Rhizaria. Nature 532: 444-445.

Caron, D.A., Michaels, A.F., Swanberg, N.R., and Howse, F. A. (1995) Primary productivity by symbiont-bearing planktonic sarcodines (Acantharia, Radiolaria, Foraminifera) in surface waters near Bermuda. J Plankton Res 17: 103129. https://doi.org/10.1093/plankt/17.1.103

Clode, P.L., Saunders, M., Maker, G., Ludwig, M., and Atkins, C.A. (2009) Uric acid deposits in symbiotic marine algae. Plant Cell Environ 32: 170-177.

Cotte, M., Pouyet, E., Salomé, M., Rivard, C., De Nolf, W., Castillo-Michel, H., et al. (2017) The ID21 X-ray and infrared microscopy beamline at the ESRF: status and recent applications to artistic materials. J Anal At Spectrom 32: 477-493.

Davy, S.K., Allemand, D., and Weis, V.M. (2012) Cell biology of cnidarian-dinoflagellate symbiosis. Microbiol Mol Biol Rev 76: 229-261.

de Vargas, C., Audic, S., Henry, N., Decelle, J., Mahe, F., Logares, R., et al. (2015) Eukaryotic plankton diversity in the sunlit ocean. Science 348: 1261605.

Decelle, J., Colin, S., and Foster, R.A. (2015) Photosymbiosis in marine planktonic protists. In Marine Protists: Diversity and Dynamics, Ohtsuka, S., Suzaki, T., Horiguchi, T., Suzuki, N., and Not, F. (eds). Japan, Tokyo: Springer, pp. 1-637. 10.1007/978-4-431-55130-0_19

Decelle, J., Probert, I., Bittner, L., Desdevises, Y., Colin, S., de Vargas, C., et al. (2012) An original mode of symbiosis in open ocean plankton. Proc Natl Acad Sci U S A 109: 18000-18005.

Decelle, J., Stryhanyuk, H., Gallet, B., Veronesi, G., Schmidt, M., Balzano, S., et al. (2019) Algal remodeling in a ubiquitous planktonic photosymbiosis. Curr Biol 29: 968-978.e4.

Decelle, J., Veronesi, G., Gallet, B., Stryhanyuk, H., Benettoni, P., Schmidt, M., et al. (2020) Subcellular chemical imaging: new avenues in cell biology. Trends Cell Biol 30: 173-188. https://doi.org/10.1016/j.tcb.2019.12.007

Dennett, M.R., Caron, D.A., Michaels, A.F., Gallager, S.M., and Davis, C.S. (2002) Video plankton recorder reveals high abundances of colonial radiolaria in surface waters of the central north pacific. J Plankton Res 24: 797-805. https://doi.org/10.1093/plankt/24.8.797

Engel, B.D., Schaffer, M., Cuellar, L.K., Villa, E., Plitzko, J. M., and Baumeister, W. (2015) Native architecture of the Chlamydomonas chloroplast revealed by in situ cryoelectron tomography. Elife 4: e04889.

Faure, E., Not, F., Benoiston, A.S., Labadie, K., Bittner, L., and Ayata, S.D. (2019) Mixotrophic protists display contrasted biogeographies in the global ocean. ISME $J 13$ : 1072-1083.

Gautier, A., Michel-Salamin, L., Tosi-Couture, E., McDowall, A. W., and Dubochet, J. (1986) Electron microscopy of the chromosomes of dinoflagellates in situ: confirmation of Bouligand's liquid crystal hypothesis. J Ultrastruct Res Mol Struct Res 97: 10-30.

Geider, R., and La Roche, J. (2002) Redfield revisited: variability of $\mathrm{C}: \mathrm{N}: \mathrm{P}$ in marine microalgae and its biochemical basis Redfield revisited: variability of $\mathrm{C}: \mathrm{N}: \mathrm{P}$ in marine microalgae and its biochemical basis. Eur $J$ Phycol 37: 1-17.

Genty, B., Briantais, J.M., and Baker, N.R. (1989) The relationship between the quantum yield of photosynthetic electron transport and quenching of chlorophyll fluorescence. Biochim Biophys Acta - Gen Subj 990: 87-92. https://doi.org/10.1016/S0304-4165(89)80016-9

Giordano, M., Norici, A., and Hell, R. (2005) Sulfur and phytoplankton: acquisition, metabolism and impact on the environment. New Phytol 166: 371-382. doi: 10.1111/j. 1469-8137.2005.01335.x.

Gornik, S.G., Hu, I., Lassadi, I., and Waller, R.F. (2019) The biochemistry and evolution of the dinoflagellate nucleus. Microorganisms 7: 245.

Guidi, L., Chaffron, S., Bittner, L., Eveillard, D., Larhlimi, A., Roux, S., et al. (2016) Plankton networks driving carbon export in the oligotrophic ocean. Nature 532: 465-470.

Gutierrez-Rodriguez, A., Pillet, L., Biard, T., SaidAhmad, W., Amrani, A., Simó, R., and Not, F. (2017) Dimethylated sulfur compounds in symbiotic protists: a potentially significant source for marine DMS(P). Limnol Oceanogr 62: 1139-1154.

Hennies, J., Lleti, J.M.S., Schieber, N.L., Templin, R.M., Steyer, A.M., and Schwab, Y. (2020) AMST: alignment to median smoothed template for focused ion beam scanning electron microscopy image stacks. Sci Rep 10: 1-10.

Karl, D.M., Church, M.J., Dore, J.E., Letelier, R.M., and Mahaffey, C. (2012) Predictable and efficient carbon sequestration in the North Pacific Ocean supported by symbiotic nitrogen fixation. Proc Natl Acad Sci U S A 109: 1842-1849.

Kashiv, Y., Austin, J.R., Lai, B., Rose, V., Vogt, S., and ElMuayed, M. (2016) Imaging trace element distributions in single organelles and subcellular features. Sci Rep 6: 21437.

Kikinis, R., Pieper, S.D., and Vosburgh, K.G. (2014) 3D slicer: a platform for subject-specific image analysis, visualization, and clinical support. In Intraoperative imaging and image-guided therapy. New York, NY: Springer New York, pp. 277-289.

Kopp, C., Domart-Coulon, I., Escrig, S., Humbel, B.M., Hignette, M., and Meibom, A. (2015) Subcellular investigation of photosynthesis-driven carbon assimilation in the symbiotic reef coral Pocillopora damicornis. MBio 6: 1-9.

Kopp, C., Pernice, M., Domart-Coulon, I., Djediat, C., Spangenberg, J.E., Alexander, D.T.L., et al. (2013) Highly dynamic cellular-level response of symbiotic coral to a sudden increase in environmental nitrogen. MBio 4: 1-9.

Lekieffre, C., Jauffrais, T., Geslin, E., Jesus, B., Bernhard, J. M., Giovani, M.E., and Meibom, A. (2018) Inorganic carbon and nitrogen assimilation in cellular compartments of a benthic kleptoplastic foraminifer. Sci Rep 8: 1-12.

LeKieffre, C., Spero, H.J., Fehrenbacher, J.S., Russell, A.D., Ren, H., Geslin, E., and Meibom, A. (2020) Ammonium is the preferred source of nitrogen for planktonic foraminifer 
and their dinoflagellate symbionts. Proc Biol Sci 287: 20200620.

Liu, Z., Mesrop, L.Y., Hu, S.K., and Caron, D.A. (2019) Transcriptome of Thalassicolla nucleata holobiont reveals details of a radiolarian symbiotic relationship. Front Mar Sci 6: 1-11.

Loussert-Fonta, C., Toullec, G., Paraecattil, A.A., Jeangros, Q., Krueger, T., Escrig, S., and Meibom, A. (2020) Correlation of fluorescence microscopy, electron microscopy, and NanoSIMS stable isotope imaging on a single tissue section. Commun Biol 3: 362.

Lowe, D.G. (2004) Distinctive image features from scaleinvariant keypoints. Int J Comput Vis 60: 91-110.

Maco, B., Cantoni, M., Holtmaat, A., Kreshuk, A., Hamprecht, F.A., and Knott, G.W. (2014) Semiautomated correlative 3D electron microscopy of in vivo-imaged axons and dendrites. Nat Protoc 9: 1354-1366.

Maruyama, S., and Weis, V.M. (2021) Limitations of using cultured algae to study cnidarian-algal symbioses and suggestions for future studies. J Phycol 57: 30-38.

Matthews, J.L., Oakley, C.A., Lutz, A., Hillyer, K.E., Grossman, A.R., Weis, V.M., and Davy, S.K. (2018) Partner switching and metabolic flux in a model cnidarian symbiodinium symbiosis. Proc $R$ Soc $B$ 285(1892). https://doi.org/10.1098/rspb.2018.2336

Martínez-Criado G., Villanova J., Tucoulou R., Salomon D., Suuronen J.-P., Labouré S., et al. (2016) ID16B: a hard Xray nanoprobe beamline at the ESRF for nano-analysis. $J$ Synchrotron Radiat, 23(1): 344-352. https://doi.org/10. 1107/s1600577515019839

Maxwell, K., and Johnson, G.N. (2000) Chlorophyll fluorescence - a practical guide. J Exp Bot 51: 659-668.

Mellman, I., and Simons, K. (1992) The Golgi complex: In vitro veritas?. Cell, 68(5): 829-840. https://doi.org/10. 1016/0092-8674(92)90027-a

Meyer, M.T., Whittaker, C., and Griffiths, H. (2017) The algal pyrenoid: key unanswered questions. J Exp Bot 68: 3739-3749.

Mojzeš, P., Gao, L., Ismagulova, T., Pilátová, J., Moudříková, Š., Gorelova, O., et al. (2020) Guanine, a high-capacity and rapid-turnover nitrogen reserve in microalgal cells. Proc Natl Acad Sci U S A 117: 32722-32730.

Moore, C.M., Mills, M.M., Arrigo, K.R., Berman-Frank, I., Bopp, L., Boyd, P.W., et al. (2013) Processes and patterns of oceanic nutrient limitation. Nat Geosci 6: 701-710.

Moore, K.L., Lombi, E., Zhao, F.J., and Grovenor, C.R.M. (2012) Elemental imaging at the nanoscale: NanoSIMS and complementary techniques for element localisation in plants. Anal Bioanal Chem 402: 3263-3273.

Morel, F.M.M., Milligan, A.J., and Saito, M.A. (2003) Marine bioinorganic chemistry: the role of trace metals in the oceanic cycles of major nutrients. In Henry Elderfield (ed.), Treatise on Geochemistry, Vol. 6. Elsevier, pp. 113-143. https://doi.org/10.1016/B0-08-043751-6/06108-9

Morel, F.M.M., and Price, N.M. (2003) The biogeochemical cycles of trace metals in the oceans. Science 300 : 944-947.

Passarelli, M.K., Pirkl, A., Moellers, R., Grinfeld, D., Kollmer, F., Havelund, R., et al. (2017) The 3D OrbiSIMS - label-free metabolic imaging with subcellular lateral resolution and high mass-resolving power. Nat Methods 14: 1175-1183.

Polerecky, L., Adam, B., Milucka, J., Musat, N., Vagner, T., and Kuypers, M.M.M. (2012) Look@NanoSIMS - a tool for the analysis of nanoSIMS data in environmental microbiology. Environ Microbiol 14: 1009-1023.

Probert, I., Siano, R., Poirier, C., Decelle, J., Biard, T., Tuji, A., et al. (2014) Brandtodinium gen. nov. and B. nutricula comb. Nov. (Dinophyceae), a dinoflagellate commonly found in symbiosis with polycystine radiolarians. J Phycol 50: 388-399.

Rädecker, N., Pogoreutz, C., Voolstra, C.R., Wiedenmann, J., and Wild, C. (2015) Nitrogen cycling in corals: the key to understanding holobiont functioning? Trends Microbiol 23: 1-8.

Raina, J.B., Clode, P.L., Cheong, S., Bougoure, J., Kilburn, M.R., Reeder, A., et al. (2017) Subcellular tracking reveals the location of dimethylsulfoniopropionate in microalgae and visualises its uptake by marine bacteria. Elife 6: 1-17.

Raina, J.B., Dinsdale, E.A., Willis, B.L., and Bourne, D.G. (2010) Do the organic sulfur compounds DMSP and DMS drive coral microbial associations? Trends Microbiol 18: 101-108.

Reich, H.G. (2020) Endosymbiotic dinoflagellates pump iron: differences in iron and other trace metal needs among the Symbiodiniaceae Endosymbiotic dinoflagellates pump iron: differences in iron and other trace metal needs among the Symbiodiniaceae. Coral Reefs 39: 915-927.

Rodriguez, I.B., Lin, S., Ho, J., and Ho, T.Y. (2016) Effects of trace metal concentrations on the growth of the coral endosymbiont Symbiodinium kawagutii. Front Microbiol 7: $1-10$.

Sbalzarini, I.F., and Koumoutsakos, P. (2005) Feature point tracking and trajectory analysis for video imaging in cell biology. J Struct Biol 151: 182-195.

Simó, R. (2001) Production of atmospheric sulfur by oceanic plankton: biogeochemical, ecological and evolutionary links. Trends Ecol Evol 16: 287-294.

Solé, V.A., Papillon, E., Cotte, M., Walter, P., and Susini, J. (2007) A multiplatform code for the analysis of energydispersive X-ray fluorescence spectra. Spectrochim Acta - Part B At Spectrosc 62: 63-68.

Stryhanyuk, H., Calabrese, F., Kümmel, S., Musat, F., Richnow, H.H., and Musat, N. (2018) Calculation of single cell assimilation rates from sip-nanosims-derived isotope ratios: a comprehensive approach. Front Microbiol 9: 1-15.

Swanberg, N.R., and Caron, D.A. (1991) Patterns of sarcodine feeding in epipelagic oceanic plankton. J Plankton Res 13: 287-312.

Thompson, A.W., Foster, R.A., Krupke, A., Carter, B.J., Musat, N., Vaulot, D., et al. (2012) Unicellular cyanobacterium symbiotic with a single-celled eukaryotic alga. Science 337: 1546-1550.

Twining, B.S., and Baines, S.B. (2013) The trace metal composition of marine phytoplankton. Ann Rev Mar Sci 5: 191-215.

Uwizeye, C., Decelle, J., Jouneau, P., Flori, S., Gallet, B., Keck, J., et al. (2021a) Morphological bases of phytoplankton energy management and physiological 
responses unveiled by $3 \mathrm{D}$ subcellular imaging. Nat Commun 12: 1049.

Uwizeye, C., Mars Brisbin, M., Gallet, B., Chevalier, F., Charlotte, L., Schieber, N., et al. (2021b) Cytoklepty in the plankton: a host strategy to optimize the bioenergetic machinery of endosymbiotic algae. Proc Natl Acad Sci $U$ $S$ A 118: e2025252118. 10.1073/pnas.2025252118

Villar, E., Dani, V., Bigeard, E., Linhart, T., MendezSandin, M., Bachy, C., et al. (2018) Symbiont chloroplasts remain active during bleaching-like response induced by thermal stress in Collozoum pelagicum (Collodaria, Retaria). Front Mar Sci 5: 1-11.

\section{Supporting Information}

Additional Supporting Information may be found in the online version of this article at the publisher's web-site:

Fig. S1. Correlation between volume of pyrenoid and volume of plastids $(\mu \mathrm{m} 3)$ of free-living and symbiotic microalgae (Brandtodinium) after FIB-SEM imaging and 3D reconstruction. ( $R=0.81, p=0.028$; Pearson correlation).

Fig. S2. The non-photochemical quenching (NPQ) parameter indicated that the light energy absorption of symbiotic microalgae Brandtodinium (blue line; $n=4$ ) was less sensitive in high-light conditions than it was in free-living phase grown in culture (red line; $n=4$ ).

Fig. S3. Distribution of heterochromatin volume of free-living and symbiotic microalgae Brandtodinium (colour coded: red bars correspond to high numbers of heterochromatin). Heterochromatin, which includes rod-shaped chromosomes and condensed chromatin present in the nucleus, has been reconstructed in 3D after FIB-SEM imaging and its volume quantified. In free-living, we observed a high number of protruding small condensed chromatin structures in the nucleus compared to symbiosis.

Fig. S4. Observation with light microscopy (A), nanoSIMS $\left({ }^{14} \mathrm{~N}^{12} \mathrm{C} /{ }^{12} \mathrm{C}_{2}\right.$ ratio) (B) and Transmission Electron microscopy (C) of dividing microalgal cells (Brandtodinium) embedded in the gelatinous matrix of the Collodaria (host).

Fig. S5. Correlated Transmission Electron microscopy ( $A$ and $B$ ) with nanoSIMS images showing relative assimilation $(\log (k a))$ of carbon $(C$ and $G)$ and nitrogen $(D$ and $H)$ in symbiotic microalgae Brandtodinium and in the Golgi apparatus (highlighted by a red circle) of the host cell (Collodaria).

Fig. S6. Subcellular quantitative mapping with nanoSIMS of natural nitrogen and phosphorous in the free-living and symbiotic stage of Brandtodinium. A and B: Nitrogen $\left({ }^{12} \mathrm{C}^{14} \mathrm{~N} /{ }^{12} \mathrm{C}_{2}\right)$ mapping in the free-living $(A)$ and symbiotic (B) stages. Note that part the host cell is visible in $B$ and the symbiotic microalga is indicated by a green arrow. $\mathrm{D}$ and $\mathrm{E}$ : Phosphorous $\left({ }^{31} \mathrm{P} /{ }^{12} \mathrm{C}_{2}\right)$ mapping in the free-living (D) and symbiotic $\left(E\right.$, green arrow) stages. Nitrogen $\left({ }^{12} C^{14} N /{ }^{12} C_{2}\right)$ and phosphorous $\left({ }^{31} \mathrm{P} /{ }^{12} \mathrm{C}_{2}\right)$ content in different organelles (plastids, nucleus, pyrenoid and chromatin) of free-living (light green) and symbiotic (dark green) microalgae. ( $\mathrm{n}$ : nucleus; nu: nucleolus; py: pyrenoid; p: plastid; h: host cell (Collodaria); m: matrix; v: vacuoles in the matrix) (See also Table S3).

Fig. S7. Metallome analyses of Collodaria (containing symbiotic microalgae, Brandtodinium) showing the intracellular metal quotas normalized against phosphorus as the biomass indicator (mmol of metal $\mathrm{mol}^{-1}$ of $\mathrm{P}$ ). Al: Aluminium, $\mathrm{Mn}$ : Manganese, Fe: iron, Ni: nickel, Zn: Z = zinc, Co: cobalt, $\mathrm{Cu}$ : copper, Cd: cadmium. Bloom sample correspond to a pool of different collodarian colonies, Collo 1, 6 and 7 are individual colonies and sample 3387 represents the freeliving microalgae Brandtodinium from culture medium. (See also Table S1).

Fig. S8. Subcellular quantitative mapping using S-XRF (Synchrotron X-ray Fluorescence) of copper (Cu) showing its concentration (ppm) in free-living (A), and symbiotic microalga Brandtodinium (B) with a xy resolution of $50 \mathrm{~nm}$ and at 7.3 keV. Note that $\mathrm{Cu}$ was below the detection level in freeliving while in symbiosis it was concentrated in condensed chromatin and vacuoles closed to plastids. C: Average SXRF spectrum per pixel in subcellular compartments (chloroplasts, pyrenoid and condensed chromatin or DNA) of Brandtodinium in free-living (black lines) and symbiotic (red lines) stages, showing high $\mathrm{Cu}$ concentration in condensed chromatin and vacuoles of symbiotic microalgae. Osmium peak is not interfering with $\mathrm{Cu}$ as such concentration.

Table S1. Morphometric data of Brandtodinium cells in freeliving and symbiotic stages.

Table S2. Nanosims data of stable isotope labeling $\left({ }^{13} \mathrm{C}\right.$ and $\left.{ }^{15} \mathrm{~N}\right)$.

Table S3. Nanosims data of natural abundance of nitrogen and phosphorous in cells.

Table S4. Sulfur and Iron concentration and distribution in cells measured by Synchrotron X-ray Fluoresence imaging.

Table S5. Bulk analyses of metal concentration (metallome) in collodaria and Brandtodinium cells.

Video S1. Live imaging in time-lapse of a Collodaria showing the movement of symbiotic microalgae within the colony. 